\title{
Development of a Pneumatic High-Angle-of-Attack Flush Airdata Sensing (HI-FADS) System
}

Stephen A. Whitmore

NASA Dryden Flight Research Facility, Edwards, California

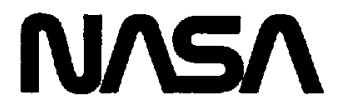

National Aeronautics and

Space Administration

Dryden Fllght Research Facillty

Edwards, California 93523-0273 


\section{CONTENTS}

$\begin{array}{lc}\text { ABSTRACT } & 1\end{array}$

NOMENCLATURE

$\begin{array}{lr}\text { INTRODUCTION } & 2\end{array}$

$\begin{array}{lr}\text { VEHICLE DESCRIPTION } & 4\end{array}$

RESEARCH MEASUREMENT AQUISITION SYSTEM 44

FLOW ANALYSIS AND PRESSURE MODELING 6

Pressure Coefficient Model For Incompressible Potential Flow On A Hemisphere . . . . . . . . . . . . 6

Effects Caused By Aircraft Induced Upwash And Sidewash . . . . . . . . . . . . . . . . . 7

CALIBRATION OF HI-FADS SYSTEM $\quad 8$

Estimation Of Calibration Parameters Using Reference Airdata . . . . . . . . . . . . . . . . . . 8

Calibration Results . . . . . . . . . . . . . . . . . . . . . . . . . . . . . 9

HIGH-ANGLE-OF-ATTACK FLUSH AIRDATA SENSING ALGORITHM 11

Matrix Equations And Least Squares Solution . . . . . . . . . . . . . . . . . . . . . . . 12

Failure Detection And Fault Tolerance Techniques . . . . . . . . . . . . . . . . . . . . . . . 13

EVALUATION OF HI-FADS SYSTEM PERFORMANCE 16

$\begin{array}{lr}\text { PROPOSED FUTURE WORK } & 23\end{array}$



$\begin{array}{lr}\text { REFERENCES } & 23\end{array}$ 


\section{ABSTRACT}

A nonintrusive high-angle-of-attack flush airdata sensing system was installed and flight tested on the F-18 High Alpha Research Vehicle at the NASA Dryden Flight Research Facility. This system consists of a matrix of 25 pressure orifices arranged in concentric circles on the nose of the vehicle to determine angles of attack and sideslip, Mach number, and pressure altitude. During the course of the flight tests, it was determined that satisfactory results could be achieved using a subset of just nine ports.

The high-angle-of-attack flush airdata sensing system was calibrated and demonstrated using reference airdata generated by way of minimum variance estimation techniques which blended airdata measurements from two wingtip airdata booms with inertial velocities, aircraft angular rates and attitudes, precision radar tracking, and meteorological analyses. Calibration results are presented.

Although analyses were not performed onboard in real-time, the High Alpha Research Vehicle high-angleof-attack flush airdata sensing system and resulting airdata algorithms were validated as being real-time capable using flight data in ground based simulations. Algorithm implementation, failure detection modes using a $\chi^{2}$ "goodness-of-fit" test, and fault tolerance techniques using weighted least squares are described.

Flight-test results are presented. Under moderate maneuvering conditions the high-angle-of-attack flush airdata sensing system was shown to give excellent results. Empirical verification was performed over a large portion of the High Alpha Research Vehicle flight envelope with a Mach number range from 0.15 to 1.20 and an angle-of-attack range from -8.0 to $55.0^{\circ}$. Angle-of-sideslip excursions covered the range from -15.0 to $15.0^{\circ}$.

\section{NOMENCLATURE}

$\begin{array}{ll}A & \text { first aerodynamic model coefficient } \\ B & \text { second aerodynamic model coefficient } \\ C & \text { linearized observation matrix } \\ C_{p} & \text { pressure coefficient } \\ \text { ESP } & \text { electronically scanned pressure } \\ F[\ldots] & \text { aerodynamic model functional } \\ \text { HARV } & \text { High Alpha Research Vehicle } \\ \text { HI-FADS } & \text { high-angle-of-attack flush airdata sensing } \\ \text { INS } & \text { inertial navigation system } \\ i & \text { high-angle-of-attack flush airdata sensing port index } \\ j & \text { iteration index } \\ M_{\infty} & \text { freestream Mach number } \\ N & \text { total number of high-angle-of-attack flush airdata sensing pressure observations being used } \\ P_{\infty} & \text { freestream static pressure } \\ \text { PCM } & \text { pulse code modulation } \\ p & \text { high-angle-of-attack flush airdata surface pressure } \\ Q & \text { least squares weighting function } \\ q_{c_{\infty}} & \text { freestream compressible dynamic pressure } \\ \bar{q}_{\infty} & \text { freestream incompressible dynamic pressure }\end{array}$


surface position vector

RMS root mean square

$V \quad$ velocity vector

$X \quad$ high-angle-of-attack flush airdata sensing state vector

$Z \quad$ high-angle-of-attack flush airdata sensing pressure observation vector

$\alpha$

generic angle of attack, deg

$\alpha_{e} \quad$ effective angle of attack, deg

$\alpha_{\infty} \quad$ freestream angle of attack, deg

$\beta \quad$ generic angle of sideslip, deg

$\beta_{e} \quad$ effective angle of sideslip, deg

$\beta_{\infty} \quad$ freestream angle of sideslip, deg

$\Delta \alpha \quad$ angle-of-attack residual, deg

$\delta \alpha$

angle-of-attack calibration parameter, $\left(\alpha_{e}-\alpha_{\infty}\right)$, deg

$\Delta \beta$

angle-of-sideslip residual, deg

$\delta \beta$

angle-of-sideslip calibration parameter, $\left(\beta_{e}-\beta_{\infty}\right)$, deg

$\triangle M \quad$ Mach number residual

$\Delta P \quad$ high-angle-of-attack flush airdata sensing pressure residual

$\delta X \quad$ state vector iteration error

$\delta Z \quad$ model prediction iteration error

$\chi^{2} \quad$ chi-square variable

$\boldsymbol{\epsilon}$

high-angle-of-attack flush airdata sensing model calibration factor

$\epsilon_{M} \quad$ variation of $\epsilon$ with Mach number

$\epsilon_{\alpha} \quad$ variation of $\epsilon$ with effective angle of attack

$\theta \quad$ flow incidence angle, deg

$\lambda \quad$ high-angle-of-attack flush airdata sensing normal angle coordinate, deg

$\sigma \quad$ standard deviation of high-angle-of-attack flush airdata sensing pressure vector

$\phi \quad$ high-angle-of-attack flush airdata sensing clock angle coordinate, deg

\section{INTRODUCTION}

Current requirements in aircraft performance and maneuver capability have dramatically complicated the problem of flight-control augmentation. This is especially true at high-angles of attack where small changes in angle of attack can greatly influence the aerodynamic properties of the aircraft. To study aerodynamics at high-angle of attack, a flight-test program with the F-18 High Alpha Research Vehicle (HARV) is being conducted at the NASA Dryden Flight Research Facility. Preliminary flights are now concluded. To accomplish the program research objectives, highly accurate airdata measurements were required throughout the entire subsonic flight envelope. At high-angles of attack it is difficult to accurately measure airdata using traditional sensing devices such as nosebooms, moreover a noseboom installation would alter the basic flow characteristics of the aircraft nose. Since flow visualization and aircraft parameter identification at high-angles of attack were major HARV program objectives, it was critical that 
this flow not be altered with a noseboom (1). ${ }^{1}$ As a means of circumventing this difficulty, a nonintrusive highangle-of-attack flush airdata sensing (HI-FADS) system was installed and flight tested on the HARV. A schematic of the HI-FADS hardware arrangement is presented in figure 1.

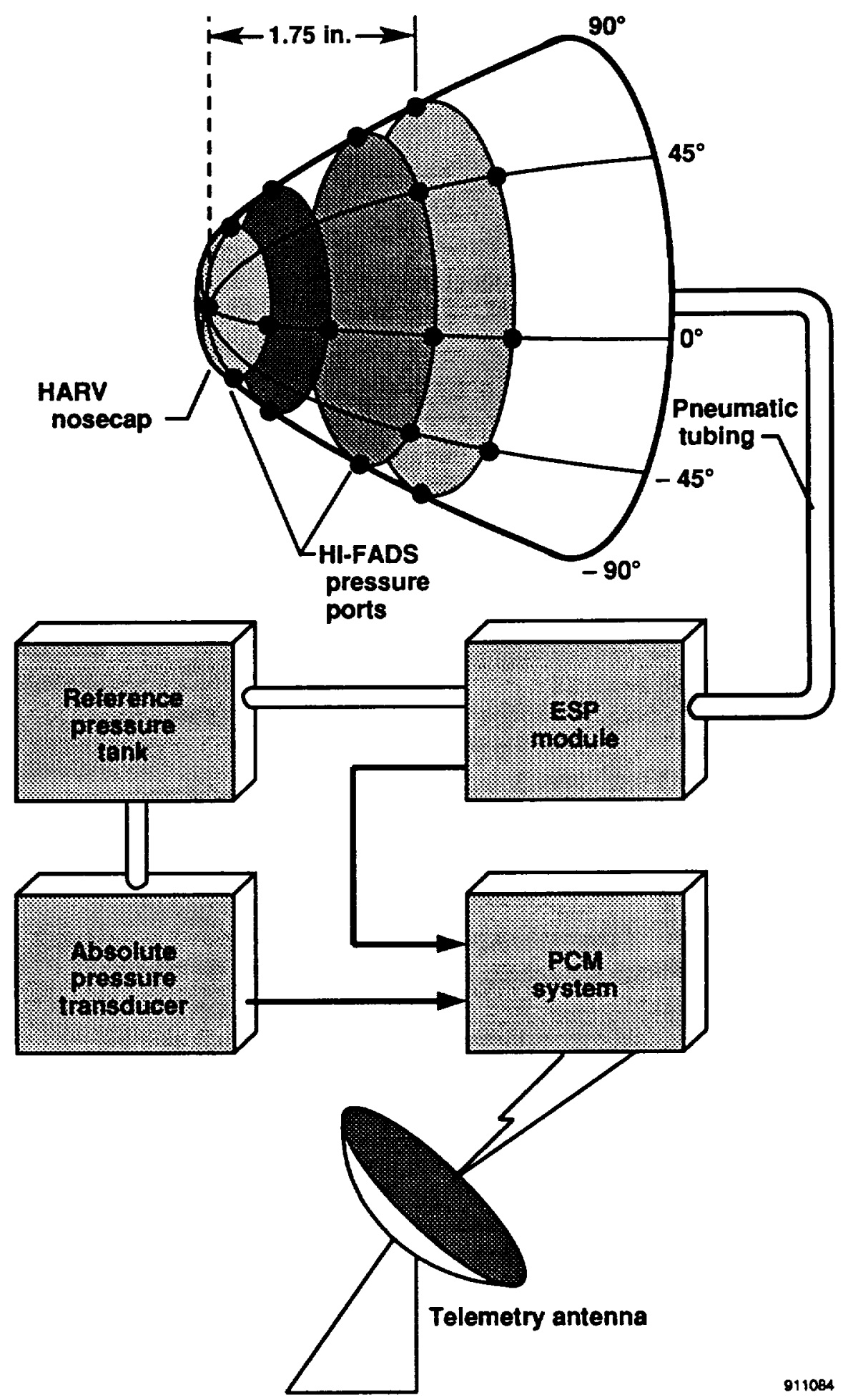

Figure 1. Schematic of HI-FADS system hardware.

\footnotetext{
${ }^{1}$ Numbers in parentheses designate references at end of paper.
} 
Additionally, since the baseline airdata system for the National Aero-Space Plane (NASP) is currently intended to be a hybrid system deriving blended airdata from pneumatic flush airdata sensing (FADS) and inertial guidance data, the HI-FADS system provided the opportunity to research various application techniques for nonintrusive airdata systems as vehicle or mission critical flight systems. Although analyses presented in this paper were not performed onboard in real time, the HARV HI-FADS system and resulting airdata algorithms were validated as being real-time capable using flight data in ground based batch simultations.

The HI-FADS system design is an evolution of prototype nonintrusive systems demonstrated in previous flight research studies $(2,3,4)$. References (3) and (4) present individual orifice pressure coefficient data for similar arrays on other aircraft. This paper emphasizes the airdata algorithm development and composite results expressed as airdata parameter estimates. This paper briefly describes the HI-FADS system hardware and calibration, the algorithm development, and proposed redundancy management techniques. Empirical verification was performed over a large portion of the HARV flight envelope with a Mach number range from 0.15 to 1.20 and an angle-of-attack range from -8.0 to $55.0^{\circ}$. Angle-of-sideslip excursions covered the range from -15.0 to $15.0^{\circ}$. Test altitudes ranged from 18,000 to $40,000 \mathrm{ft}$. Selected portions of this database will be presented.

Data illustrating the performance of the system under nominal conditions are presented first. Nominal performance statistics are presented. Next, the effects of failure detection and fault tolerance techniques are illustrated using flight data subjected to large spikes. For this illustration, the algorithm diverged without fault tolerance protection. With fault protection, the algorithm performed well.

\section{VEHICLE DESCRIPTION}

The HARV is a single-place F-18 aircraft featuring dual engines and a mid-wing with leading- and trailingedge flaps. The flight-test noseboom has been removed to make way for the HI-FADS installation. The wingtip sidewinder launch racks have been removed and replaced with special camera pods and wingtip airdata booms. For flight safety during the initial HARV flight tests, the vehicle was limited to $55^{\circ}$-angle of attack. A broad overview of the F-18 HARV program is given in reference 5.

\section{RESEARCH MEASUREMENT AQUISITION SYSTEM}

For the HARV flight tests, a special research measurement aquisition system was installed. This system provided flight research measurements in addition to the nominal data provided by the aircraft flight systems sensors. Research system measurements included linear accelerations from a set of body-axis accelerometers; pitch, roll, and yaw attitudes from a gimbaled attitude gyro, three-axis angular velocities from a body-axis rate-gyro package, airdata from two calibrated wingtip airdata booms, and pressure data from the HI-FADS system. In addition to these measurements, velocity, aircraft attitudes, and altitude from the aircraft inertial navigation system (INS) were also interfaced with the research measurement aquisition system. All data were digitally encoded onboard using pulse code modulation (PCM) and telemetered to ground where they were displayed in real time and recorded for post-flight analysis.

As mentioned earlier, the wingtip airdata booms were installed specifically for the HARV flight tests. The right wingtip airdata boom consisted of a standard NACA pitot-static head with flow direction vanes $(6,7,8)$. The left wingtip airdata boom consisted of a specially constructed swivel-head designed to align with the local air-velocity vector. This swivel design effectively eliminated total pressure loss at high-angles of attack. Flow direction sensing vanes were also installed on the left wingtip boom. Both wingtip booms were calibrated to a steady-state bias accuracy of better than \pm 0.005 in Mach number and $\pm 0.5^{\circ}$ in angle of attack and sideslip. Calibration validity range for the wingtip airdata sensors extended up to $40.0^{\circ}$-angle of attack. Beyond $40.0^{\circ}$-angle of attack, the accuracy 
of the wingtip sensor measurements diminished rapidly. Specific details concerning the wingtip sensor hardware, installation, and calibration are presented in references 9 and 10.

The HI-FADS configuration has a simple hardware arrangement with the basic fixture being a small fiberglass reinforced plastic nosecap. A set of 250.06 -in. diameter pressure orifices, arranged in annular rings, was drilled in the nosecap. Flight tests were conducted using a 25-port arrangement with ports arranged in 4 rings and a single nosetip port. The rings were distributed in a symmetric radial pattern about the nosecap axis of symmetry. Analyses were performed using all 25 orifices and a subset of 9 orifices. The locations of the nosecap ports were determined using a normal and clock angle coordinate system measured relative to the axis of symmetry. The nosecap itself is biased downward at an angle of $5.6^{\circ}$ relative to the longitudinal axis of the aircraft. The normal angle, $\lambda$, is defined as the total angle that the normal to the surface makes with respect to the nosecap axis of symmetry. The clock angle, $\phi$, is defined as the angle looking aft around the axis of symmetry, measured in a clockwise sense starting at the aircraft $Z$-axis. Figure 2 illustrates the definitions of the normal and clock coordinate angle.

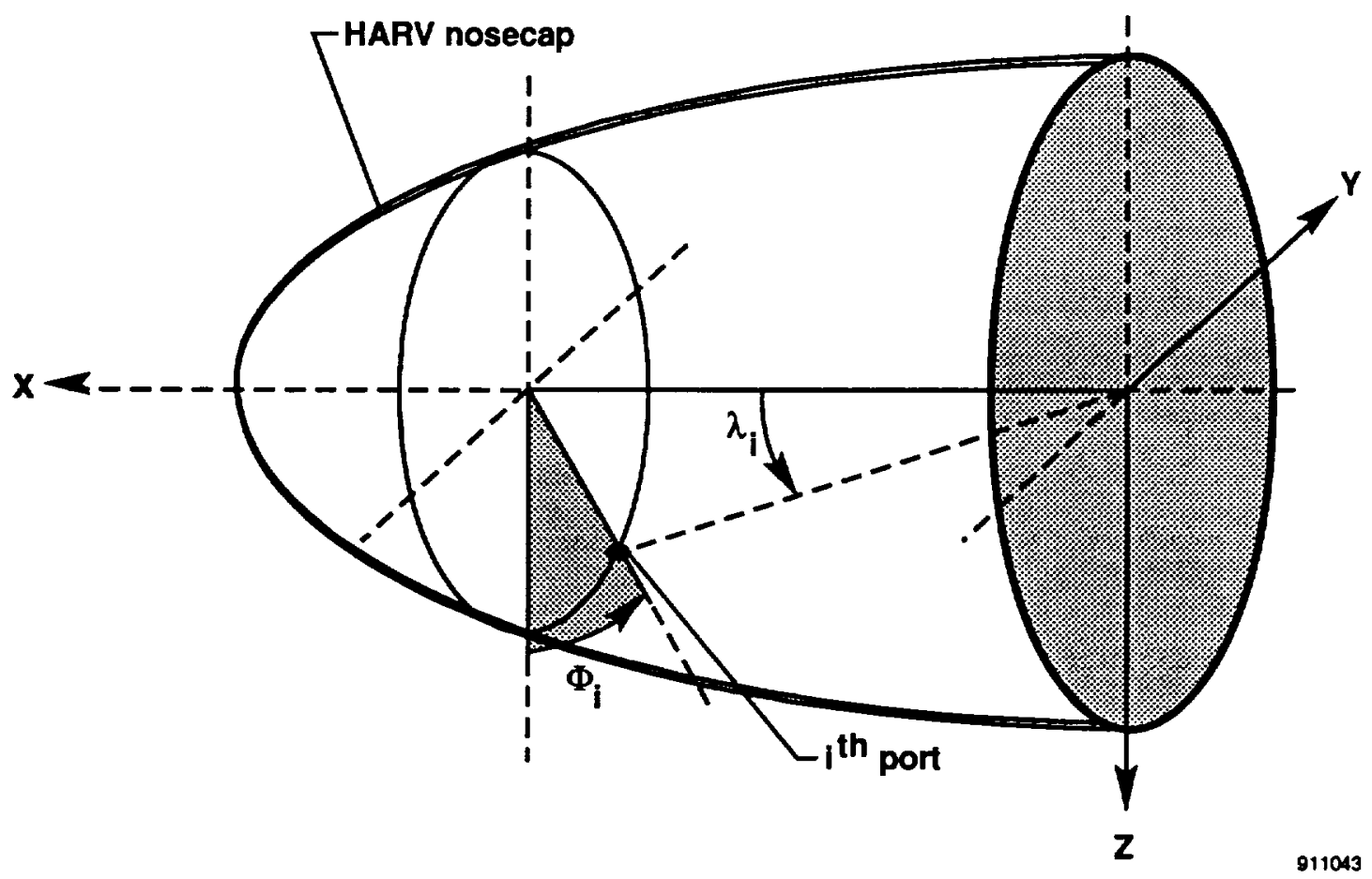

Figure 2. Coordinate definitions for $i^{\text {th }}$ HI-FADS pressure port.

Port IDs were named according to the clockwise order of occurrence within each annular ring, starting at $\phi=0$. According to this naming convention, the third clockwise port in the second ring is designated $P 203$, the fourth port in the second ring is designated P204, and so on. The coordinate angles of the various pressure ports are listed in Table 1. Ports IDs followed by an asterisk were used in both the 9-port and 25-port analyses.

The HI-FADS pressures were sensed by a multitransducer electronically scanned pressure (ESP) module remotely mounted on a structural bulkhead within the aircraft nose cavity. The backside reference pressure for the ESP module (which consists of differential pressure sensors) was measured by an absolute pressure sensor also mounted in the aircraft nose cavity. Fluctuations in the reference pressure were damped out by a reference tank. Outputs from the HI-FADS transducers were discretized by PCM, and telemetered to ground using the research measurement aquisition system. The HI-FADS pressure data were sampled at $25 \mathrm{samples} / \mathrm{sec}$. The estimated accuracy of the concatonated pressure measurements was better than $2 \mathrm{lb} / \mathrm{ft}^{2}$. 
Table 1. HARV HI-FADS pressure port locations.

\begin{tabular}{lrr}
\hline \hline Port ID & $\begin{array}{c}\text { Clock angle, } \\
\text { deg }\end{array}$ & $\begin{array}{c}\text { Normal angle, } \\
\text { deg }\end{array}$ \\
\hline p001* & 0.0 & 0.0 \\
p101 & 0.0 & 20.0 \\
p102 & 90.0 & 20.0 \\
p103 & 180.0 & 20.0 \\
p104 & 270.0 & 20.0 \\
p201 & 0.0 & 40.0 \\
p202 & 90.0 & 40.0 \\
p203 & 180.0 & 40.0 \\
p204 & 270.0 & 40.0 \\
p301* & 0.0 & 55.0 \\
p302 & 45.0 & 55.0 \\
p303* & 90.0 & 55.0 \\
p304 & 135.0 & 55.0 \\
p305* & 180.0 & 55.0 \\
p306 & 225.0 & 55.0 \\
p307* & 270.0 & 55.0 \\
p308 & 315.0 & 55.0 \\
p401 & 0.0 & 60.0 \\
p402* & 45.0 & 60.0 \\
p403 & 90.0 & 60.0 \\
p404* & 135.0 & 60.0 \\
p405 & 180.0 & 60.0 \\
p406* & 225.0 & 60.0 \\
p407 & 270.0 & 60.0 \\
p408* & 315.0 & 60.0 \\
\hline \hline
\end{tabular}

\section{FLOW ANALYSIS AND PRESSURE MODELING}

This section develops a simple aerodynamic model which is used to relate the HI-FADS pressure measurements to the desired airdata quantities. Using the developed model all available pressure measurements can be used simultaneously to estimate the complete airdata state using nonlinear regression. The use of an overdetermined (more observations than states) analysis makes the resulting algorithm robust to small perturbations in the measured pressure data.

\section{Pressure Coefficient Model For Incompressible Potential Flow On A Hemisphere}

References 11 and 12 demonstrate that for three-dimensional incompressible potential flow around sphere, the pressure coefficient at the surface is given as

$$
C_{p}(\theta)=1-\frac{9}{4} \sin ^{2}(\theta)=-\frac{5}{4}+\frac{9}{4} \cos ^{2}(\theta),
$$

where $\theta$ is the total flow incidence angle at the surface.

To account for a nonspherical nose shape, compressibility, and afterbody effects, the coefficients are allowed to assume arbitrary values while still retaining the basic form of the model, i.e.

$$
C_{p}(\theta)=A+B \cos ^{2}(\theta) .
$$


The coefficients, $A$ and $B$ are to be empirically determined. In order to satisfy conservation of momentum and energy, the stagnation pressure constraint must be enforced, i.e., when $\theta=0$,

$$
C_{p}(0)=\frac{q_{c}}{\bar{q}}=A+B
$$

This constraint may be built into the model by letting

and

$$
A=\frac{q_{c}}{\bar{q}} \epsilon
$$

$$
B=\frac{q_{c}}{\bar{q}}(1-\epsilon)
$$

Substituting these constraints for $A$ and $B$ into equation (1) and regrouping terms gives

$$
C_{p}(\theta)=\frac{q_{c}}{\bar{q}}\left[\cos ^{2}(\theta)+\epsilon \sin ^{2}(\theta)\right]
$$

thus the parameter $\epsilon$ simply represents an adjustment to modified Newtonian flow theory which is applicable to hypersonic flows (13). If $\epsilon$ is allowed to vary smoothly throughout the Mach number range, and eventually taper to zero at very high speeds, then a single model which is valid from subsonic to hypersonic conditions can be achieved.

The incidence angle may be written in terms of angle of attack and angle of sideslip by taking the inner product of the position vector with the velocity vector

$$
\begin{aligned}
\cos (\theta)= & \frac{V \cdot R}{\|V\|\|R\|} \\
= & \cos (\alpha) \cos (\beta) \cos (\lambda) \\
& +\sin (\beta) \sin (\phi) \sin (\lambda) \\
& +\sin (\alpha) \cos (\beta) \cos (\phi) \sin (\lambda)
\end{aligned}
$$

Applying the definition of the pressure coefficient

the model reduces to

$$
C_{p}(\theta)=\frac{p_{\theta}-p_{\infty}}{\bar{q}}
$$

Thus for a given location on the surface

$$
p_{\theta}=q_{c}\left[\cos ^{2}(\theta)+\epsilon \sin ^{2}(\theta)\right]+p_{\infty}
$$

$$
p(\phi, \lambda)=F\left(\alpha, \beta, q_{c}, p_{\infty}, \phi, \lambda, \epsilon\right),
$$

where $\alpha, \beta, q_{c}, P_{\infty}$ are airdata parameters, $\phi, \lambda$ are orifice coordinate angles, and $\epsilon$ is a calibration parameter yet to be empirically determined.

\section{Effects Caused By Aircraft Induced Upwash And Sidewash}

As presented earlier, the potential flow model assumes a nonlifting hemisphere with no trailing afterbody. Clearly this is not the case for the nose of an aircraft where vehicle induced upwash and sidewash alter the local flow angles (12). Thus the HI-FADS system measures local or effective $\left(\alpha_{\varepsilon}, \beta_{\varepsilon}\right)$ and not freestream $\left(\alpha_{\infty}, \beta_{\infty}\right)$ angles of attack and sideslip. Effective and freestream angles are related by

and

$$
\alpha_{e}=\alpha_{\infty}+\delta \alpha
$$

$$
\beta_{e}=\beta_{\infty}+\delta \beta
$$

where $\delta \alpha$ and $\delta \beta$ are calibration factors which must also be empirically identified. 


\section{CALIBRATION OF HI-FADS SYSTEM}

The HI-FADS system was calibrated using reference airdata generated from flight data by way of the minimum variance estimation techniques of references $14,15,16$, and 17. In this procedure, high-accuracy, highfidelity reference airdata are generated by merging complementary information from multiple data sources provided by the research data aquisition system and external measurements such as radar tracking and analyses of weather balloon information.

All flight maneuvers used to perform the calibration analyses were preceded and followed by approximately $20 \mathrm{sec}$ of stabilized low-to-moderate angle-of-attack flight. During this stabilized flight, the wingtip boom airdata were weighted heavily to give initial and final estimates of the atmospheric winds. During the course of the calibration maneuvers, filter weights were adaptively varied to weight the wingboom airdata inversely proportional to both pitch rate and angle of attack. At the same time, the equivalent time constant of the wind states was increased in direct proportion to pitch rate and angle of attack. Weights on the inertial and meteorological data were held constant throughout the maneuver. Maneuver reference airdata were generated off-line and stored for later use in the calibration analyses.

A maneuver was judged to be good for calibration purposes when the resulting wind estimates showed little or no correlation to aircraft-dependent velocity parameters. The basic premise of this technique is that atmospheric winds, although they may change during the course of a flight maneuver, should change independently of aircraft motions. Examination of filter covariance estimates indicates that the resulting reference airdata estimates have a root-mean-square (RMS) noise level of approximately 0.001 in Mach number, $0.1^{\circ}$ in angle of attack and angle of sideslip, and $10 \mathrm{ft}$ in altitude. Using these reference airdata, a procedure for identifying the HI-FADS calibration parameters, $\delta \alpha, \delta \beta$, and $\epsilon$ using nonlinear regression will now be outlined.

\section{Estimation Of Calibration Parameters Using Reference Airdata}

The calibration parameters $\delta \alpha, \delta \beta$, and $\epsilon$ were estimated by substituting the reference airdata into the flow model and comparing the model pressure predictions to the pressures which were actually measured. Residuals between the measured and predicted pressures were then used to infer the values of the calibration parameters at each data frame using nonlinear regression.

Recall that the pressure at the $i^{\text {th }}$ HI-FADS orifice is related to the flow indicence angle according to the semiempirical expression

$$
p_{i}=q_{c}\left[\cos ^{2}\left(\theta_{i}\right)+\epsilon \sin ^{2}\left(\theta_{i}\right)\right]+p_{\infty}
$$

where $\theta_{i}$ is a function of the surface location and the effective angles of attack and sideslip. Equation (2) may be written in functional form as

$$
p_{i}=F\left\{\left(\begin{array}{c}
\alpha_{e} \\
\beta_{e} \\
P_{\infty} \\
q_{c} \\
\epsilon
\end{array}\right),\left(\begin{array}{c}
\phi_{i} \\
\lambda_{i}
\end{array}\right)\right\}
$$

where

$$
\left(\begin{array}{c}
\phi_{i} \\
\lambda_{i}
\end{array}\right)
$$

is the coordinate vector for the $i^{\text {th }}$ HI-FADS orifice. If equation (3) is linearized by expanding in a power series about

$$
\left(\begin{array}{c}
\alpha_{e} \\
\beta_{e} \\
\epsilon
\end{array}\right)=\left(\begin{array}{c}
\alpha_{\infty} \\
\beta_{\infty} \\
0
\end{array}\right),
$$


truncated after first order, and evaluated using the measured pressures and reference airdata, the result may be grouped as the linear matrix system

$$
\left(\begin{array}{c}
p_{1}-F_{1_{1 \infty}} \\
p_{2}-F_{2_{1 \infty}} \\
\ldots \\
p_{N}-F_{N_{1 \infty}}
\end{array}\right)=\left(\begin{array}{ccc}
\left(\frac{\partial F_{1}}{\partial \alpha}\right)_{l_{\infty}} & \left(\frac{\partial F_{1}}{\partial \beta}\right)_{l_{\infty}} & \left(\frac{\partial F_{1}}{\partial \epsilon}\right)_{l_{\infty}} \\
\left(\frac{\partial F_{2}}{\partial \alpha}\right)_{l_{\infty}} & \left(\frac{\partial F_{2}}{\partial \beta}\right)_{l_{\infty}} & \left(\frac{\partial F_{2}}{\partial \epsilon}\right)_{l_{\infty}} \\
\ldots & \ldots & \ldots \\
\left(\frac{\partial F_{N}}{\partial \alpha}\right)_{l_{\infty}} & \left(\frac{\partial F_{N}}{\partial \beta}\right)_{l_{\infty}} & \left(\frac{\partial F_{N}}{\partial \epsilon}\right)_{l_{\infty}}
\end{array}\right) \quad\left(\begin{array}{c}
\delta \alpha \\
\delta \beta \\
\epsilon
\end{array}\right)
$$

where

$$
F_{i_{\infty}}=F\left\{\left(\begin{array}{c}
\alpha_{\infty} \\
\beta_{\infty} \\
P_{\infty} \\
q_{c_{\infty}} \\
0
\end{array}\right),\left(\begin{array}{c}
\phi_{i} \\
\lambda_{i}
\end{array}\right)\right\}
$$

and

$$
\left(\frac{\partial F_{i}}{\partial \alpha}\right)_{l_{\infty}}=\frac{\partial F}{\partial \alpha}\left\{\left(\begin{array}{c}
\alpha_{\infty} \\
\beta_{\infty} \\
P_{\infty} \\
q_{c_{\infty}} \\
0
\end{array}\right),\left(\begin{array}{l}
\phi_{i} \\
\lambda_{i}
\end{array}\right)\right\},
$$

and so on. At each data frame, equation (4) is solved for the calibration parameters $\delta \alpha, \delta \beta$, and $\epsilon$ using leastsquares regression (18). At high-angles-of-attack, the nonlinear algorithm requires iteration to convergence at each data frame. Convergence is usually reached in less than three iterations.

\section{Calibration Results}

Calibration data were obtained for Mach numbers up to 1.20 and angles of attack up to $55.0^{\circ}$. Calibrations performed for the 9-port and 25-port configurations were found to be nearly identical, thus it is concluded that the calibration is mostly influenced by the aircraft configuration and (within reason) not the individual port layout. For this paper, only results from the 9-port calibration will be presented.

Systematic trends were identified by plotting the estimated calibration parameters-the results of the regression on equation (4) -as a function of various flight variables and visually inspecting the results. Once trends were identified, a series of tabular breakpoints were derived using curve-fits, and the tables were hard-coded into the algorithm. The resulting calibration trends will now be presented. Calibration results will be presented in terms of the effective flow angles.

Calibration data for the upwash parameter are presented in figure 3, where $\delta \alpha$ is plotted against effective angle of attack. The standard deviation in $\delta \alpha$ increases with decreasing Mach number, however, $\delta \alpha$ did not trend with either Mach number or angle of sideslip in a clearly discernible systematic manner.

Similar calibration data for the sidewash parameter are presented in figure 4 , where $\delta \beta$ is plotted as a function of effective angle of sideslip. As above, the standard deviation in $\delta \beta$ increased with decreasing Mach number, similarly, $\delta \beta$ did not trend with either Mach number or angle of attack in a systematic manner.

Finally, calibration breakpoints for $\epsilon$ are presented. It was empirically determined that $\epsilon$ may be accurately decomposed into two components; $\epsilon_{M}$, which varies as a function of Mach number only, and $\epsilon_{\alpha}$, which varies as a function of (effective) angle of attack only, where,

$$
\epsilon=\epsilon_{M}+\epsilon_{\alpha}
$$




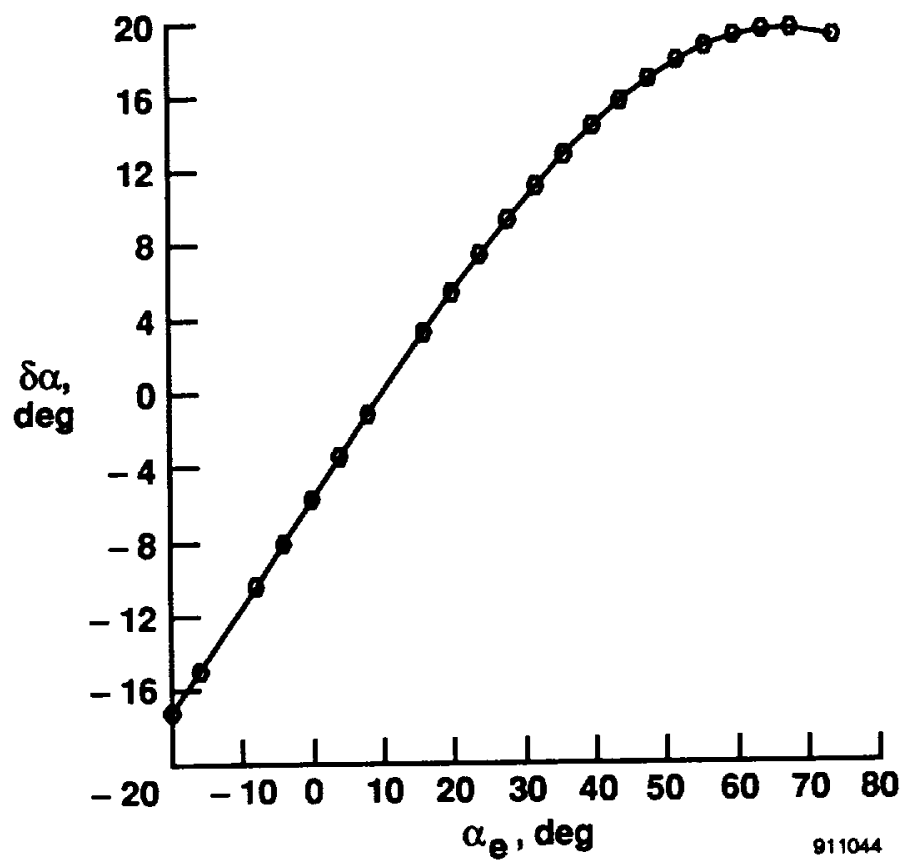

Figure 3. Calibration results: effective angle-of-attack parameter.



Figure 4. Calibration results: effective angle-of-sideslip parameter.

These breakpoints are presented in figures 5 and 6 . In figure $5, \epsilon_{M}$ is plotted against $M_{\infty}$ and in figure $6, \epsilon_{\alpha}$ is plotted against $\alpha$. Interestingly, $\epsilon_{M}$ rises smoothly through Mach 1 and then begins to decline with increasing Mach number. For the moderate angles of sideslip encountered in the HARV HI-FADS tests, no systematic trend relating angle of sideslip to $\epsilon$ was discernible. 


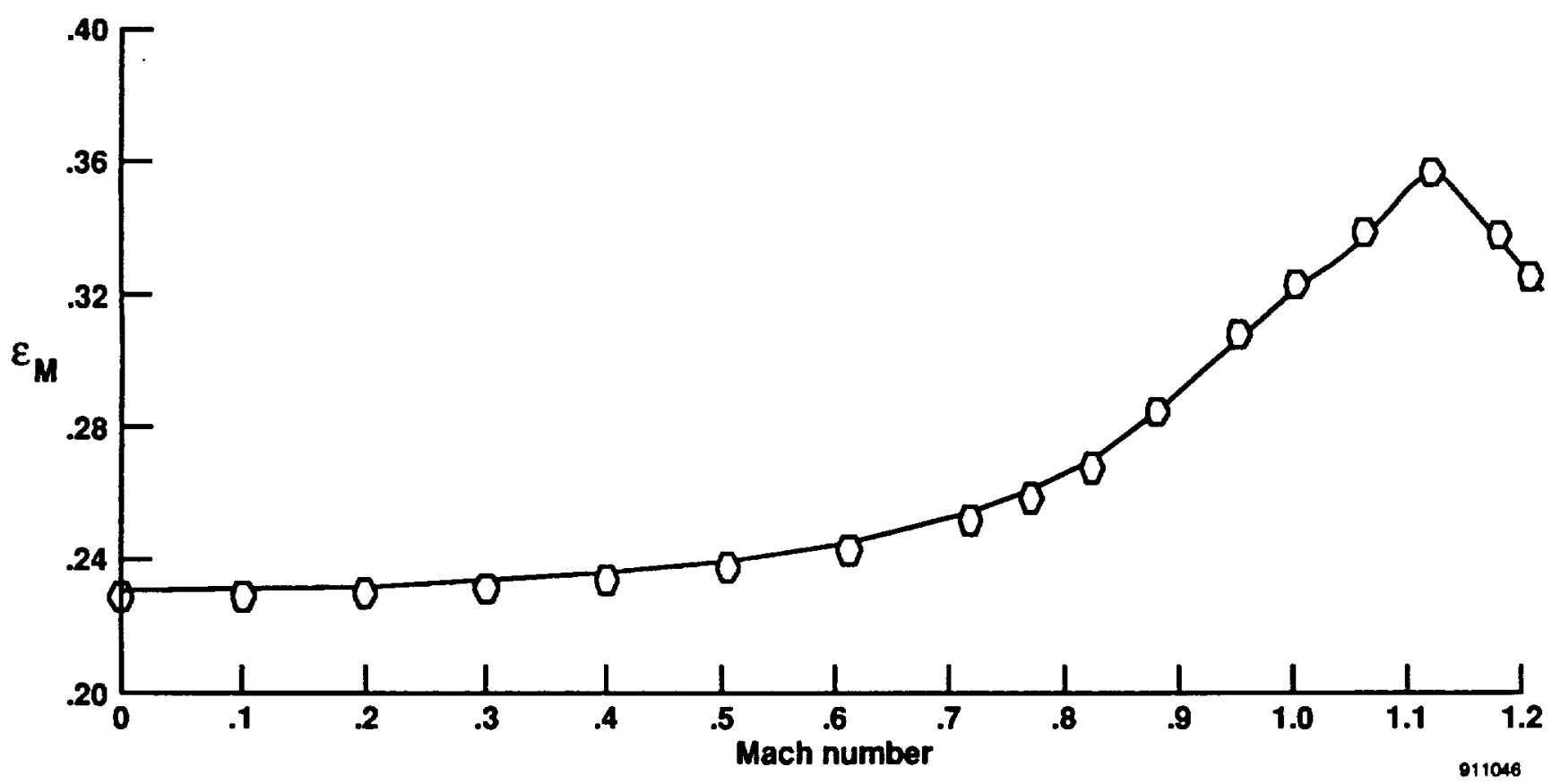

Figure 5. Calibration results: $\epsilon_{M}$ parameter.

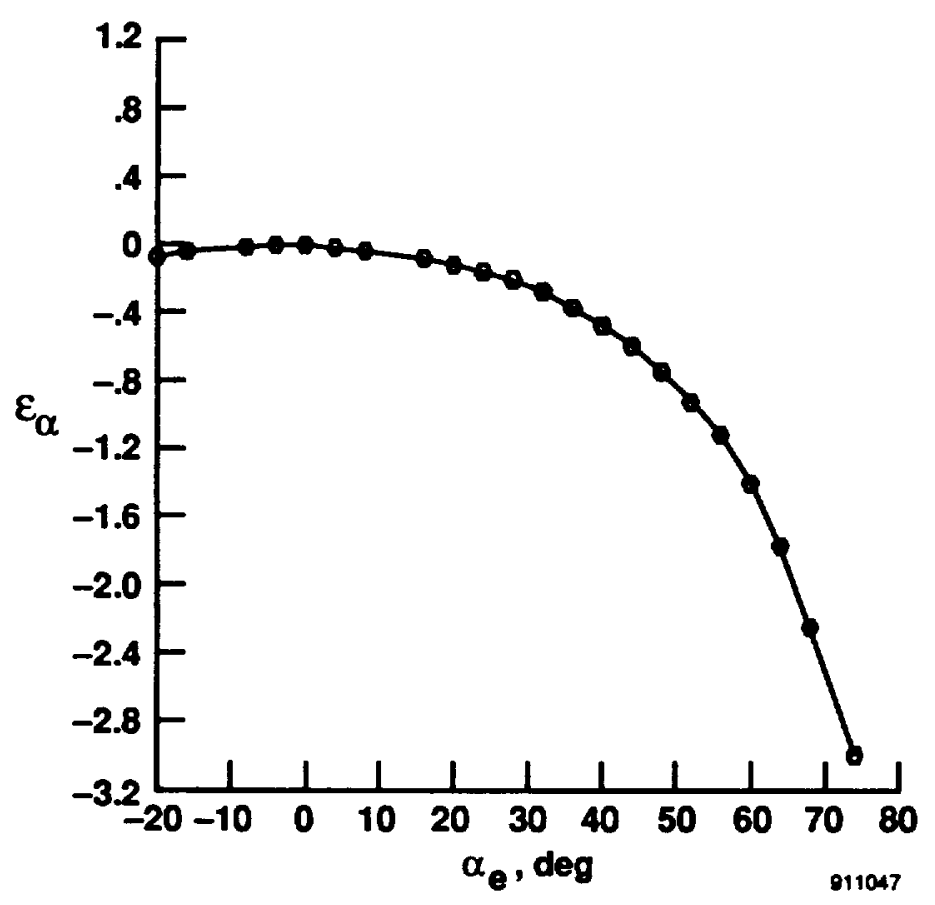

Figure 6. Calibration results: $\epsilon_{\alpha}$ parameter.

\section{HIGH-ANGLE-OF-ATTACK FLUSH AIRDATA SENSING ALGORITHM}

First, this section will derive the HI-FADS system matrix equations and the regression formulae used to solve the system. Next, failure detection and fault tolerance techniques for individual port failures will be developed. 


\section{Matrix Equations And Least Squares Solution}

Using an approach similar to that of the previous section, the algorithm to be used for determining the airdata parameters using the HI-FADS pressure data will now be developed. Assuming that an estimate of the $j^{\text {th }}$ freestream airdata state is available, then if the calibrated flow model is expanded and linearized about this estimate

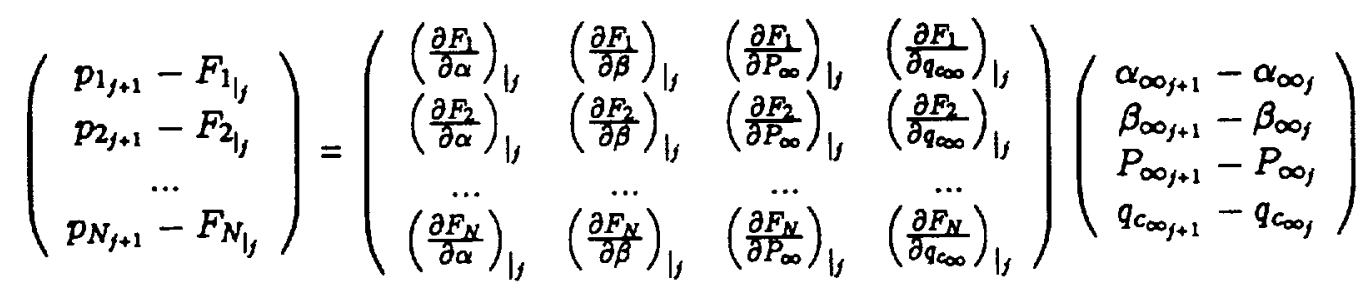

where

$$
F_{i, j}=F\left\{\left(\begin{array}{c}
\alpha_{\infty,} \\
\beta_{\infty,} \\
P_{\infty, j} \\
q_{c_{\infty j}}
\end{array}\right),\left(\begin{array}{c}
\delta \alpha \\
\delta \beta \\
\epsilon
\end{array}\right),\left(\begin{array}{l}
\phi_{i} \\
\lambda_{i}
\end{array}\right)\right\},
$$

and so on. The parameters $\delta \alpha, \delta \beta$, and $\epsilon$ are computed using the previously determined calibration tables. If the left-hand side of equation (5) is evaluated using measured pressure data, the $N$ by 4 overdetermined linear system may be written in matrix form as form as

$$
\delta Z=C \delta X+\text { error }
$$

and solved using weighted iterative least squares (18)

$$
\hat{X}_{j+1}=\hat{X}_{j}+\left[\left(C^{T} Q_{j+1} C\right)^{-1} C^{T}\right] C^{T} Q_{j+1}\left[Z_{j+1}-\hat{Z}_{j}\right]
$$

with

$$
Z_{j+1}=\left(\begin{array}{c}
p_{1 j+1} \\
p_{j+1} \\
\cdots \\
p_{N_{j+1}}
\end{array}\right), \quad \hat{Z}_{j}=\left(\begin{array}{c}
\hat{F}_{l_{l /}} \\
\hat{F}_{\psi_{j}} \\
\ldots \\
\hat{F}_{N_{l j}}
\end{array}\right)
$$

and

$$
\hat{X}_{j+1}=\left(\begin{array}{c}
\hat{\alpha}_{\infty_{j+1}} \\
\hat{\beta}_{\infty_{j+1}} \\
\hat{P}_{\infty_{j+1}} \\
\hat{q}_{c_{\infty j+1}}
\end{array}\right), \quad \hat{X}_{j}=\left(\begin{array}{c}
\hat{\alpha}_{\infty j} \\
\hat{\beta}_{\infty j} \\
\hat{P}_{\infty j} \\
\hat{q}_{\infty_{\infty j}}
\end{array}\right),
$$

and so on. Here, $Q$ is the weighting matrix for this iteration.

Within each frame, the algorithm is linearized about a starting value, the least squares state perturbations are computed, and the algorithm is iterated until convergence. At the beginning of each new data frame the system is re-linearized about the result of the previous frame, and the iteration is repeated, thus the algorithm is time-recursive as well as iterative. This recursive, iterative, and overdetermined (more observations than states) structure makes the algorithm stable and robust to small perturbations in the measured pressure data. For the initial data frame, the algorithm is initialized about an arbitrary user-input starting value. More sophisticated startup techniques are currently being investigated. 


\section{Failure Detection And Fault Tolerance Techniques}

Difficulty occurs when a large disturbance such as a data spike or a bit-dropout occurs in a measured pressure value. Recall that equation (5) is nonlinear, thus when the error is minimized by way of the least-squares algorithm, one true minimum and multiple false minima will exist. If a large disturbance is undetected and not weighted out of the regression, the resulting state perturbation may dump the algorithm into a false minimum and algorithm divergence will result. The diverged algorithm will give nonsensical results and will not reliably be able to return to the true minimum without reinitializing.

Figure 7 presents a one-dimensional illustration of the the problem of false minima. Here, when the marker lies at 1 , the algorithm is nondivergent but still needs additional iterations before convergence is reached. When the marker lies at 2, the algorithm has converged. Finally, if a large pressure disturbance were to occur, the algorithm could be dumped into a false minimum (marker at 3 ) and converge to a nonsensical answer (marker at 4).

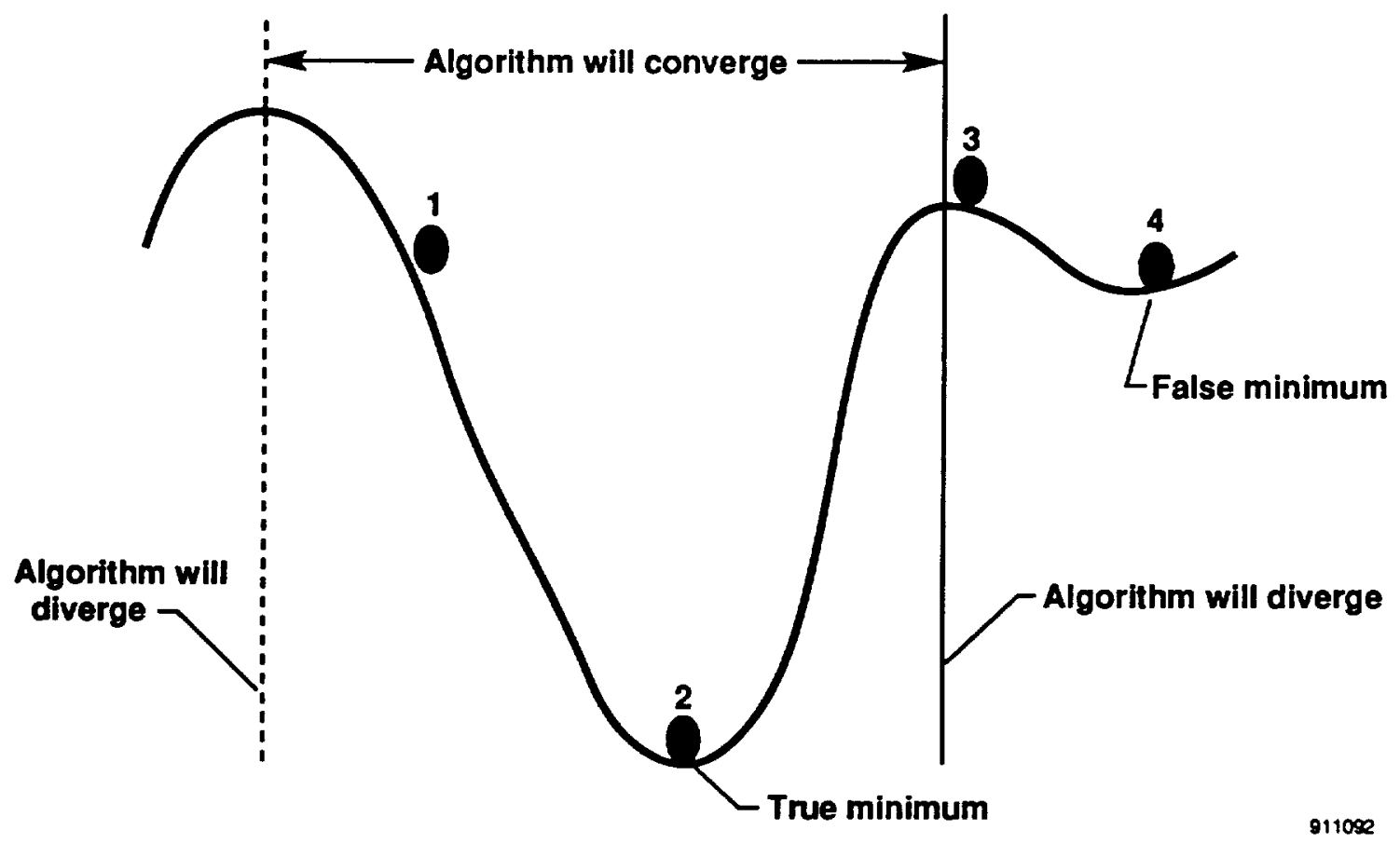

Figure 7. 1-D illustration of HI-FADS algorithm divergence due to false minima.

If a smoothed histogram of the HARV FADS pressure residuals normalized by dynamic pressure $\delta P_{i} / q_{c}$ for nonfailed, converged airdata is evaluated, the distribution of the residual is approximately zero-mean and Gaussian with a variance that is proportional to angle of attack. The sample residual variance, computed from nonfailed HI-FADS flight data, is plotted as a function of angle of attack in figure 8. Since the individual residuals are normally distributed, for a given data frame, the sum-square of the normalized residuals divided by the expected variance are distributed as a $\chi^{2}$ variable with N-6 degrees of freedom. The N-6 degrees of freedom result from dependencies amongst the derived airdata, $\chi^{2}$, and individual pressure measurements. ${ }^{2}$ Thus, prior to performing an algorithm iteration, evaluating

$$
\chi^{2}=\sum_{i=1}^{N}\left(\frac{\left(\delta P_{i} / q_{c}\right)^{2}}{\sigma^{2}}\right)
$$

where $\mathrm{N}$ is the number of ports available for that data frame, allows the hypothesis for airdata convergence to be tested. At the beginning of each frame, if the magnitude of $\chi^{2}$ is compared against percentage points of $\chi^{2}$ distribution,

\footnotetext{
${ }^{2}$ Remember that $\alpha, \beta, p_{\infty}, q_{e}, \epsilon$, and $\sigma$ have been estimated from the pressure data.
} 
then the probability that a particular value of $\chi^{2}$ can occur without airdata failure may be assessed. In fact, a low value for $\chi^{2}$ is a good indication that the algorithm has converged and another iteration is not necessary. As the HI-FADS algorithm is currently implemented, the value of $\chi^{2}$ is used as the algorithm convergence criterion.

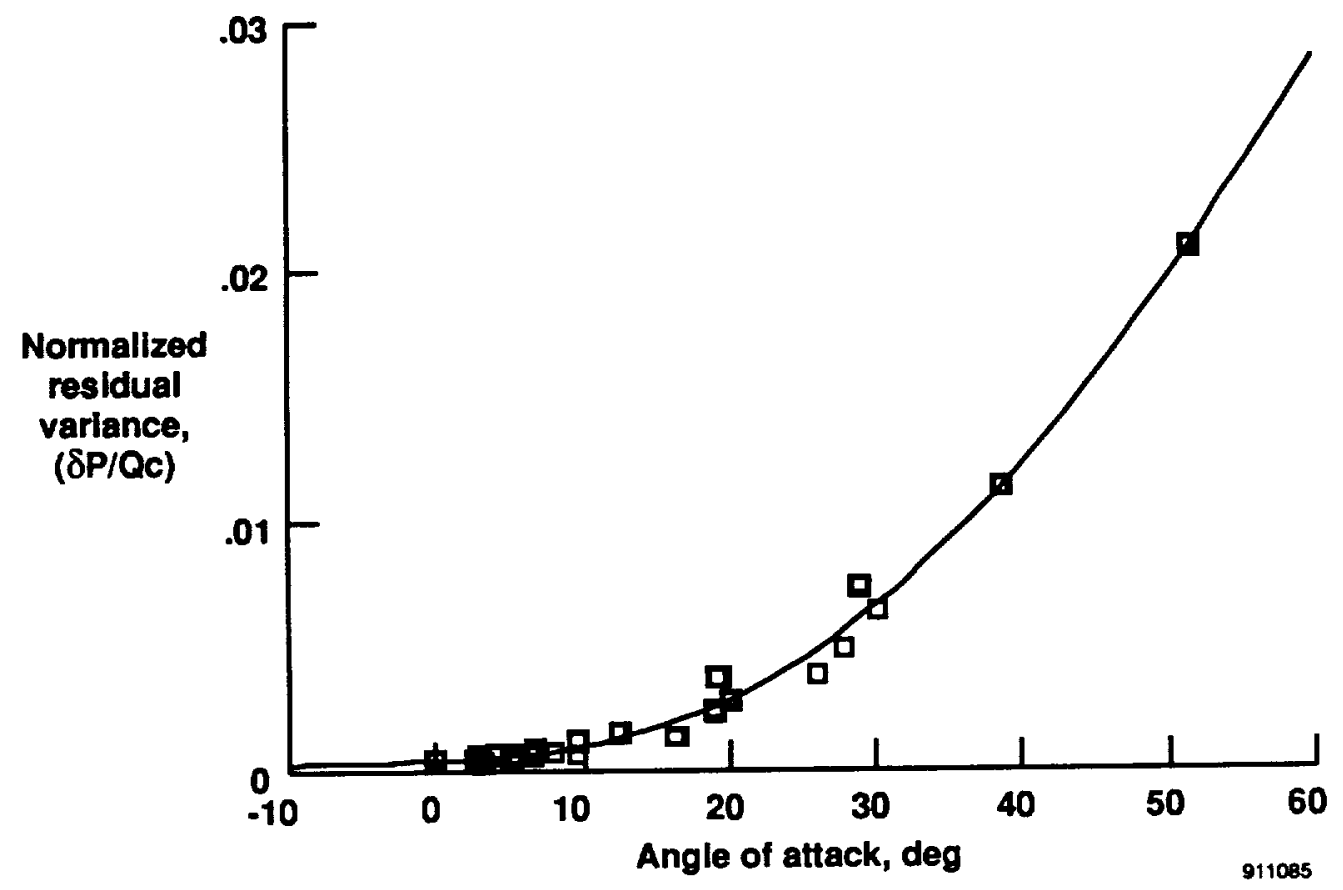

Figure 8. HI-FADS pressure residual variance.

For example, a $\chi^{2}$ value of 2 indicates a high probability that the algorithm has converged and another iteration need not be performed for this data frame. A larger value (e.g., $\chi^{2}=25$ ) indicates that the algorithm has not converged and another iteration is necessary. A high value (e.g., $\chi^{2}=250$ ) indicates a high probability of failure and individual failure detection routines need to be invoked. An extremely large value $\left(\right.$ e.g., $\chi^{2}=2500$ ) indicates a certain catastrophic failure if fault tolerance procedures are not implemented. Thus, depending upon the value of $\chi^{2}$, various iteration or failure detection modes can be initiated.

The value of this method is that it allows a nominal operation of the algorithm with little overhead for fault detection. Additionally, the $\chi^{2}$ value provides a solid convergence criterion. Only when a catastrophic measurement failure has occurred will individual pressure validity tests need to be performed. The $\chi^{2}$ test is completely reliable; for small sample populations, it is the singularly most reliable "goodness of fit test" available (19).

Figure 9(a) presents the residual histogram, derived from the nonfailed HARV flight data and normalized by the population standard deviation, compared against a unit variance Gaussian density function. Similarly, figure 9(b) presents the $\chi^{2}$ histogram compared against the theoretical $\chi^{2}$ density. In both cases data and theory are a close match; thus the $\chi^{2}$ test may be applied with confidence.

Because failure tests on individual ports need to be performed only when a $\chi^{2}$ test failure has occurred, individual failure tests can be simple, such as a $3-\sigma$ test (based on the population variance for unfailed airdata) on the individual pressure residuals; or complex, such as a parity test in which values of $\chi^{2}$ for various port groups are evaluated, and ports whose inclusion causes the chi-square value to grow inordinately are rejected. When a port has been identified as failed, then it is weighted out of the algorithm by setting its weight to zero (or some small value). For the HI-FADS tests only the simple $3-\sigma$ test for port failure was implemented. Currently, research on more sophisticated individual failure detection schemes is being performed. A block diagram of the HI-FADS algorithm flow structure is presented in figure 10 . 


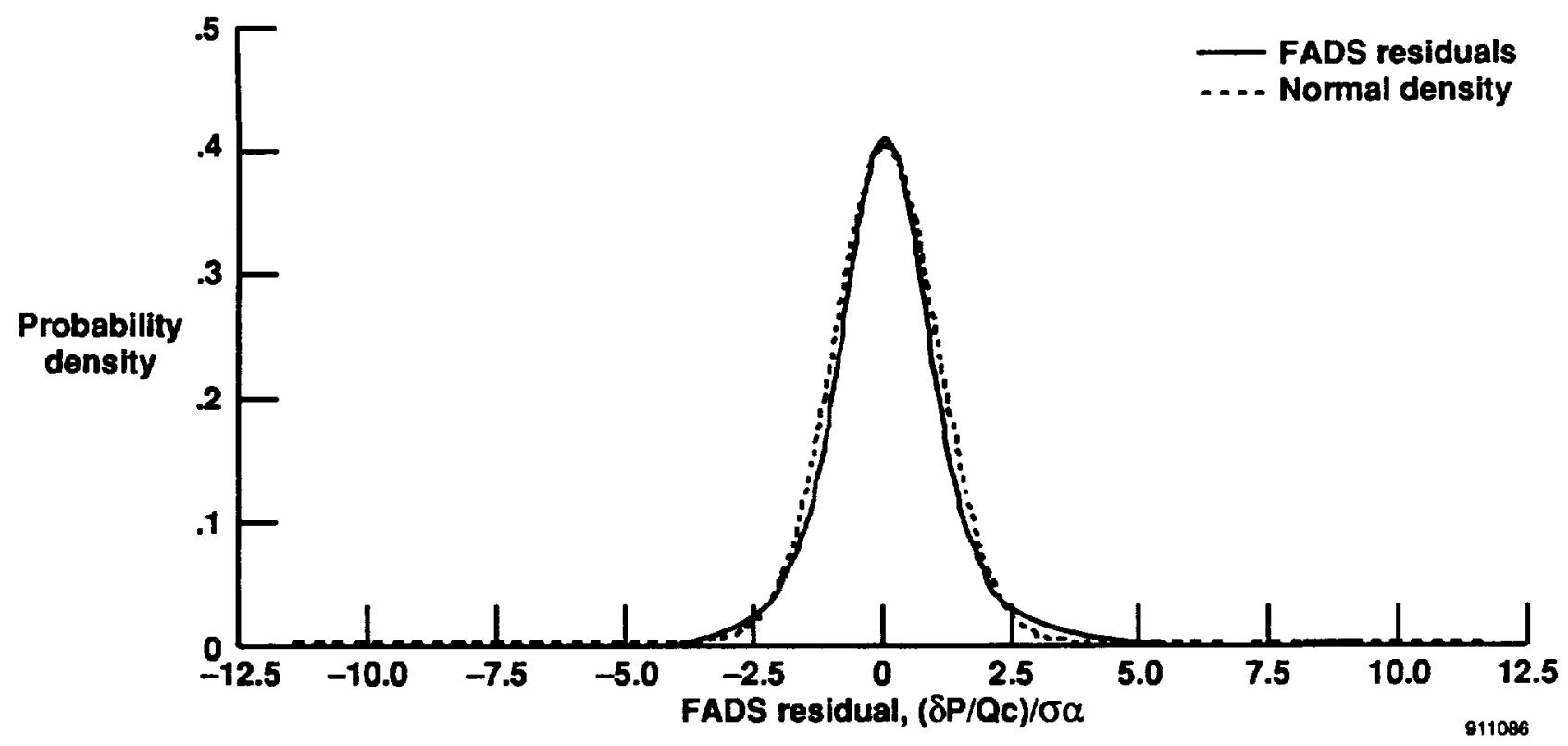

9(a) Normalized probability density for FADS residuals.

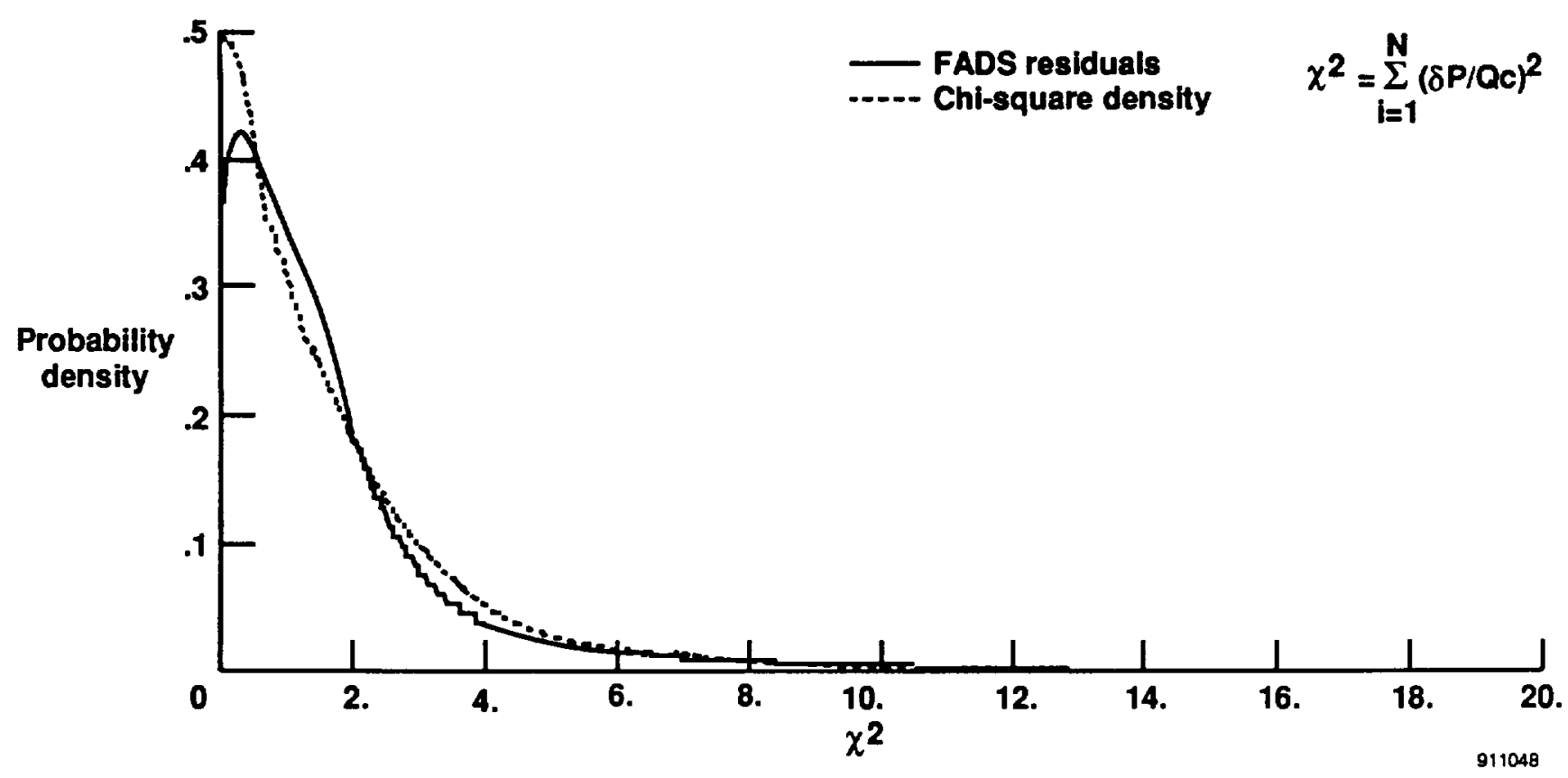

9(b) Histogram of HI-FADS $\chi^{2}$ residual data. 


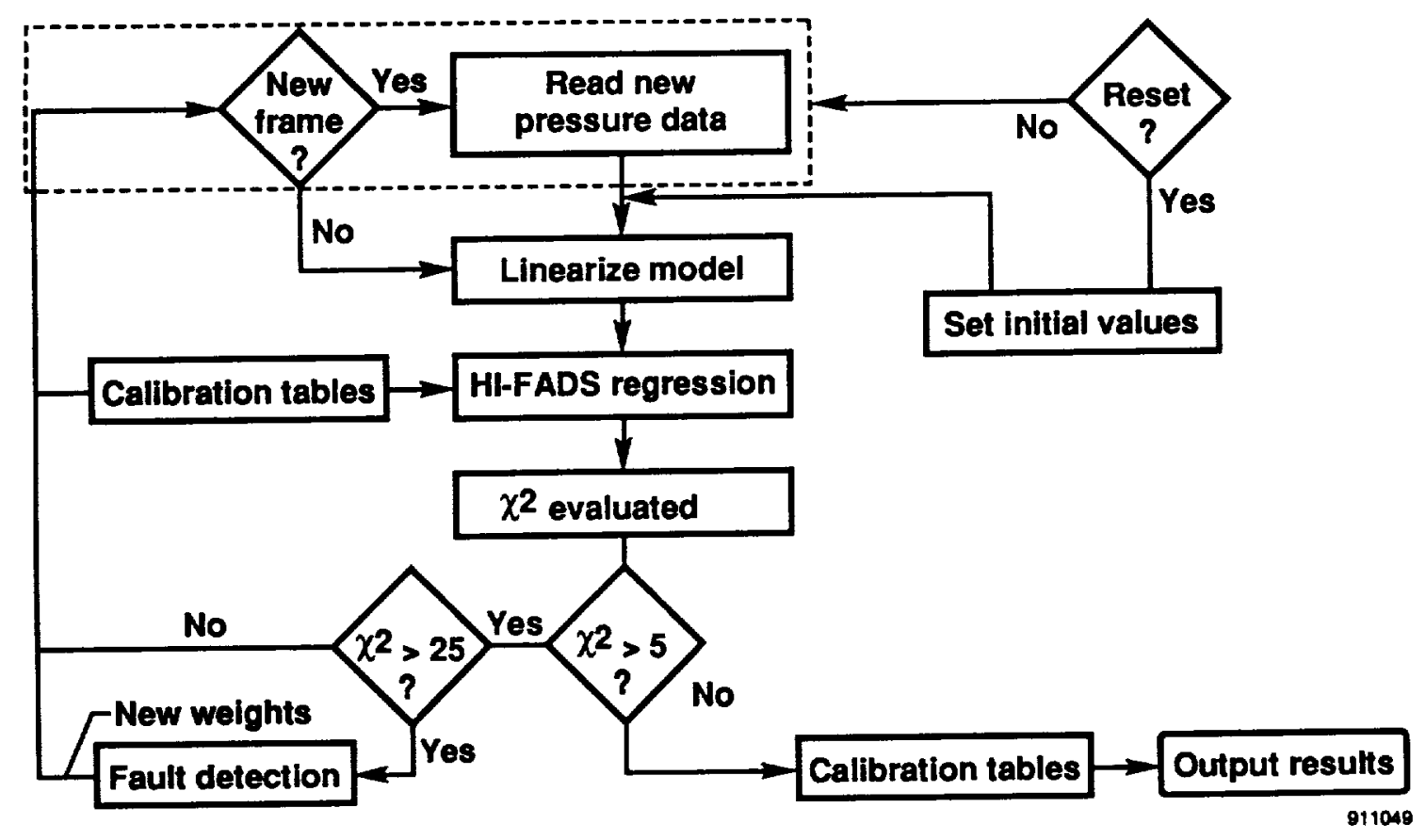

Figure 10. HI-FADS algorithm.

\section{EVALUATION OF HI-FADS SYSTEM PERFORMANCE}

The performance of the HI-FADS system was empirically evaluated using flight data, where comparisons between various HI-FADS derived airdata estimates and the corresponding reference airdata parameters were performed. The reference airdata were generated using the same minimum variance estimation techniques as described previously. As an illustration of typical flight results, data from a moderate rate dutch-roll maneuver will now be presented. These HI-FADS data, obtained using the 9-port analysis, were not previously used in establishing the calibration tables.

Comparisons of HI-FADS and reference angles of attack are shown in figure 11. Presented in figure 11(a) are the actual angle-of-attack time histories. Two curves are presented-the reference angle of attack and the HI-FADS angle of attack. For the scale used, no differences are discernible. Actual differences may be discerned by plotting the time history of the residual between the HI-FADS and reference angles of attack. This residual time history is presented in figure 11(b). Similar comparisons for Mach number and angle of sideslip are presented in figures 12(a), 12(b), 13(a), and 13(b). With the exception of small deviations during the high rate portions of the maneuver, the differences between the HI-FADS and reference airdata values are insignificant. 




Figure 11(a) Dutch roll maneuver time history comparisons: angle of attack.

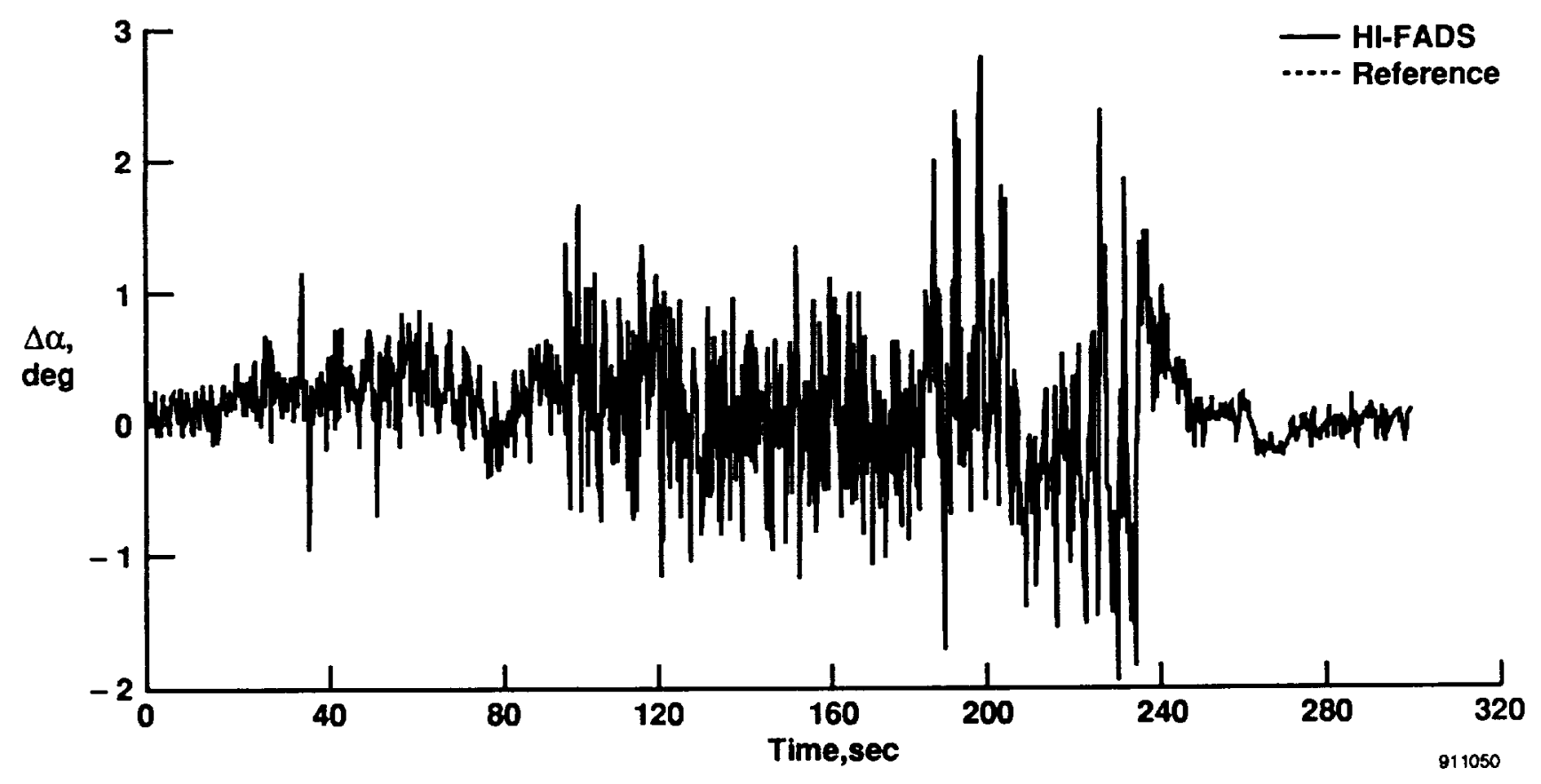

Figure 11b Dutch roll maneuver time history comparisons: residual difference. 


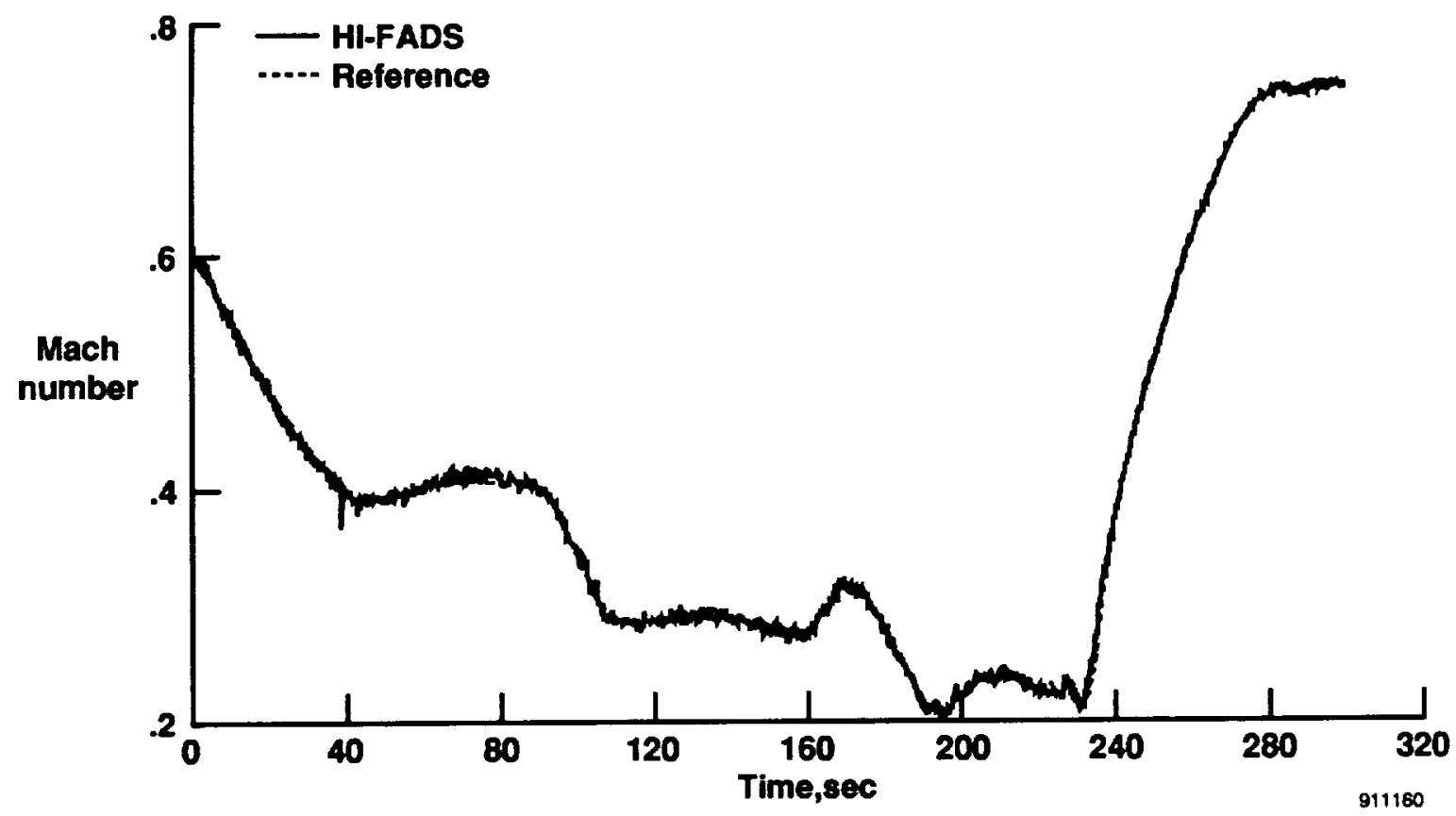

Figure 12(a) Dutch roll maneuver time history comparisons: Mach number.

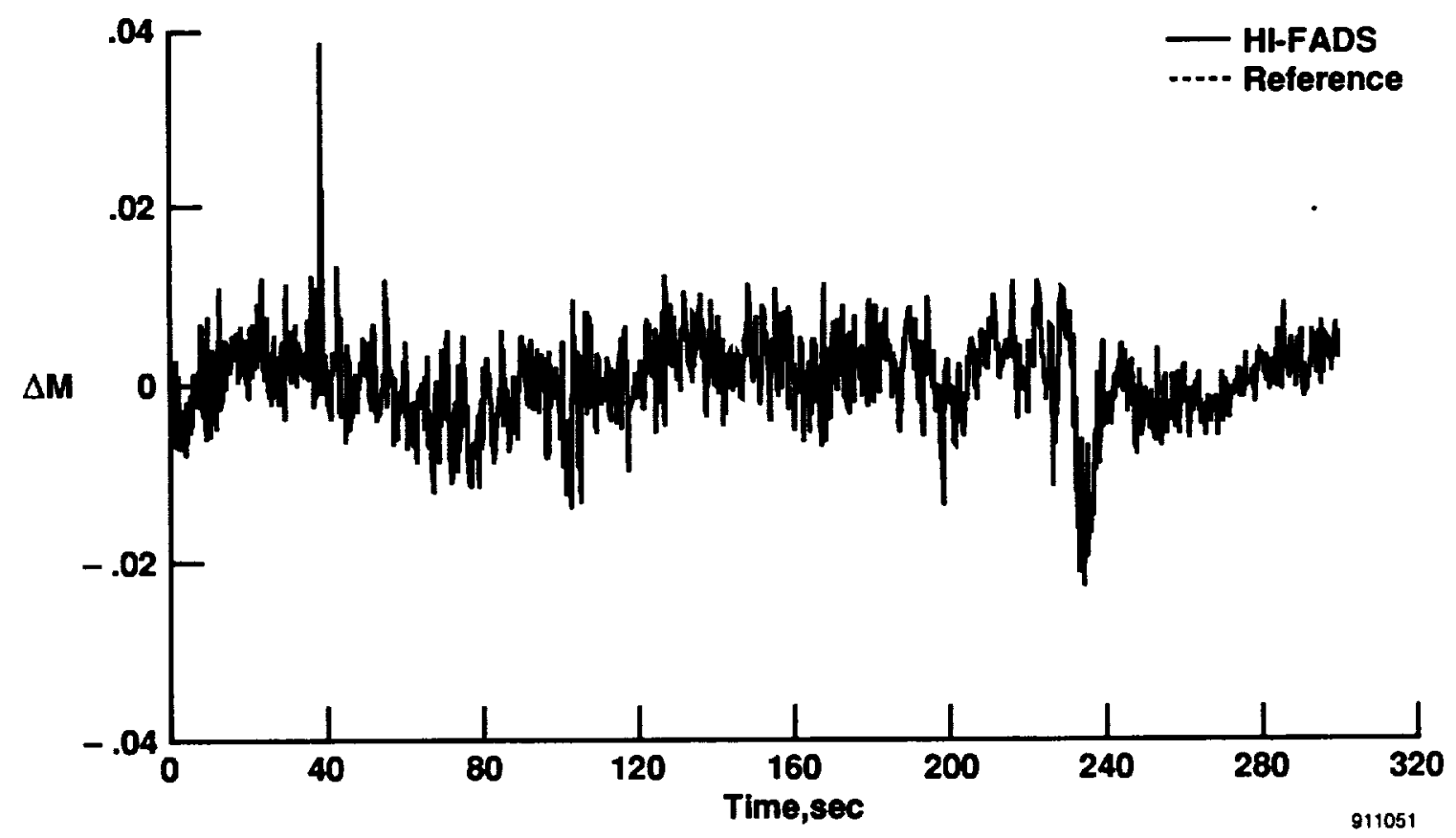

Figure 12(b) Dutch roll maneuver time history comparisons: residual difference. 


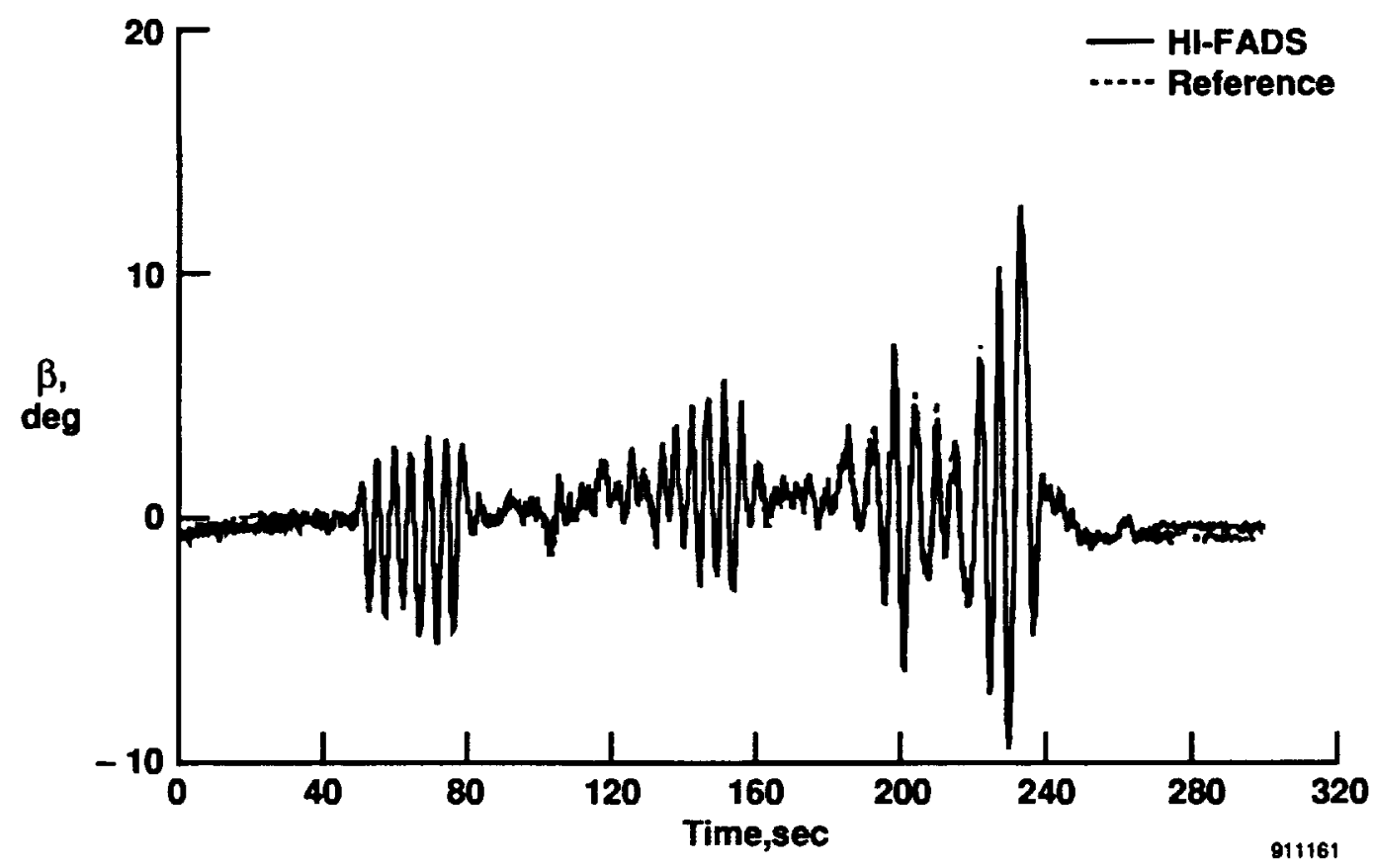

Figure 13(a) Dutch roll maneuver time history comparisons: angle of sideslip.



Figure 13(b) Dutch roll maneuver time history comparisons: residual difference. 
Quantitative accuracy levels were obtained by evaluating residual statistics for a compilation of various HI-FADS maneuvers. These results are presented in Table 2 for the 9-port and the 25-port analyses. The HI-FADS airdata estimates resulting from 25-port analyses were slightly less noisy than for the 9-port analyses. Since the 25-port configuration is more overdetermined and thus less sensitive to individual measurement errors, this result is as expected. The statistical data indicate that even up to high-angles-of-attack, both configurations have a standard deviation of approximately one-half degree in angle of attack and angle of sideslip, and better than 0.004 in Mach number. On a steady-state basis, the extremely low mean residual values indicate that the HI-FADS system can be calibrated as accurately as the reference against which it is being compared.

Table 2. HARV HI-FADS airdata residual statistics for 9-port and 25-port configurations.

\begin{tabular}{lcccc}
\hline \hline \multicolumn{1}{c}{ Parameter } & $\begin{array}{c}\text { Mean error } \\
\text { 9-port }\end{array}$ & $\begin{array}{c}\text { RMS error } \\
\text { 9-port }\end{array}$ & $\begin{array}{c}\text { Mean error } \\
\text { 25-port }\end{array}$ & $\begin{array}{c}\text { RMS error } \\
\text { 25-port }\end{array}$ \\
\hline Angle of attack & $0.02^{\circ}$ & $0.56^{\circ}$ & $0.02^{\circ}$ & $0.48^{\circ}$ \\
Angle of sideslip & $0.10^{\circ}$ & $0.52^{\circ}$ & $0.10^{\circ}$ & $0.46^{\circ}$ \\
Mach number & 0.0008 & 0.004 & 0.0007 & 0.003 \\
Altitude & $11.4 \mathrm{ft}$ & $19.2 \mathrm{ft}$ & $9.2 \mathrm{ft}$ & $16.3 \mathrm{ft}$ \\
& $(3.47 \mathrm{~m})$ & $(5.85 \mathrm{~m})$ & $(2.80 \mathrm{~m})$ & $(4.97 \mathrm{~m})$ \\
Airspeed & $0.84 \mathrm{ft} / \mathrm{sec}$ & $4 \mathrm{ft} / \mathrm{sec}$ & $0.75 \mathrm{ft} / \mathrm{sec}$ & $3 \mathrm{ft} / \mathrm{sec}$ \\
& $(0.259 \mathrm{~m} / \mathrm{sec})$ & $(1.22 \mathrm{~m} / \mathrm{sec})$ & $(0.223 \mathrm{~m} / \mathrm{sec})$ & $(0.914 \mathrm{~m} / \mathrm{sec})$ \\
\hline
\end{tabular}

Application of the $\chi^{2}$ test to prevent algorithm divergence is now illustrated using actual F-18 HARV flight data. Here the incoming pressures experienced a series of sharp data spikes of large magnitude. Time histories of the pressures are presented in figure 14. When these data are run unprotected through the FADS algorithm, catastrophic divergence results. The results are presented in figure 15(a) for the computed angle-of-attack time history. For the diverged data, the computed $\chi^{2}$ time history is presented in figure 15(b). At divergence, $\chi^{2}$ assumes large values.

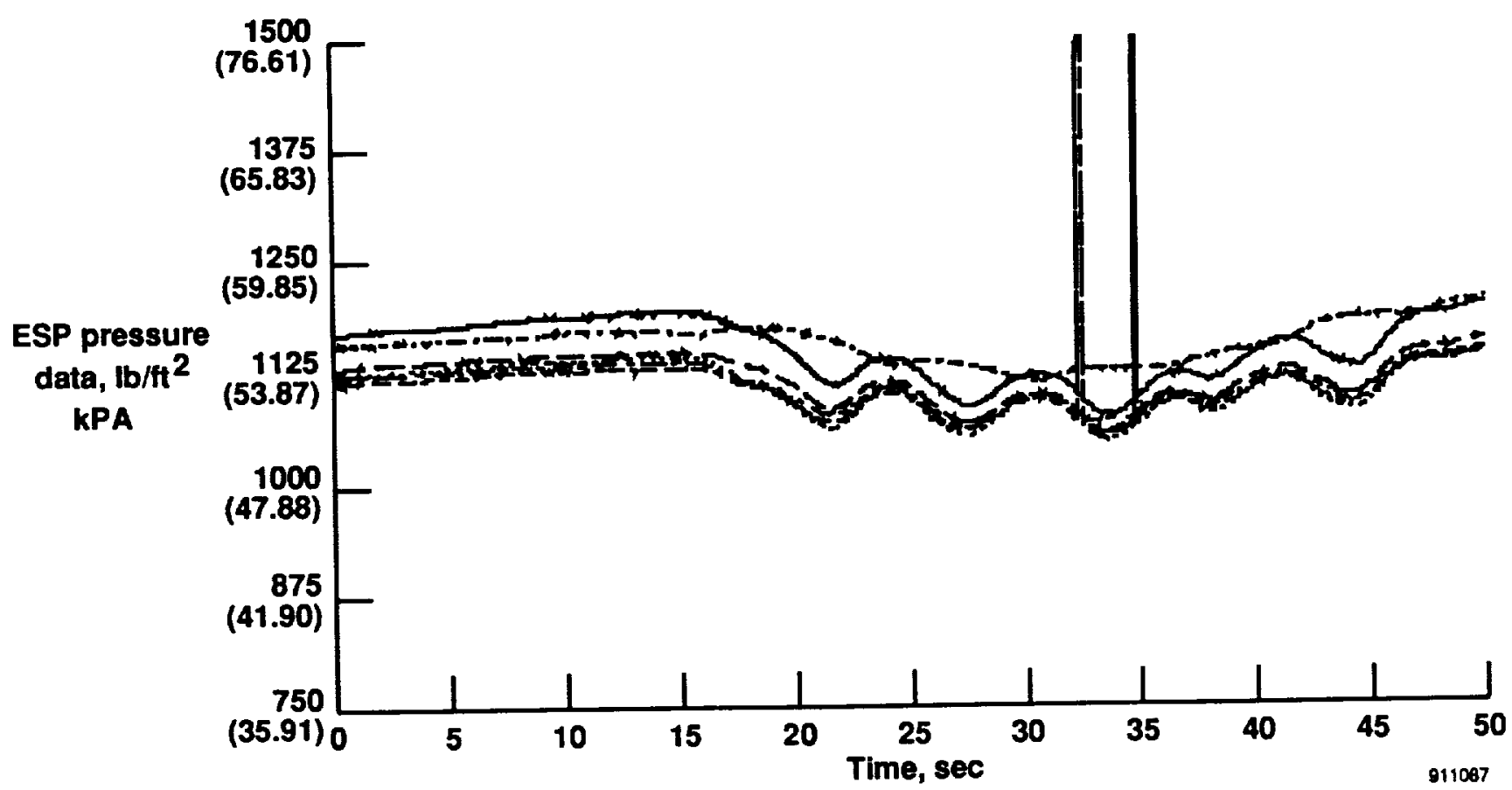

Figure 14. ESP pressure data for airdata failure example. 




Figure 15(a) Failed HI-FADS airdata (no divergence protection).

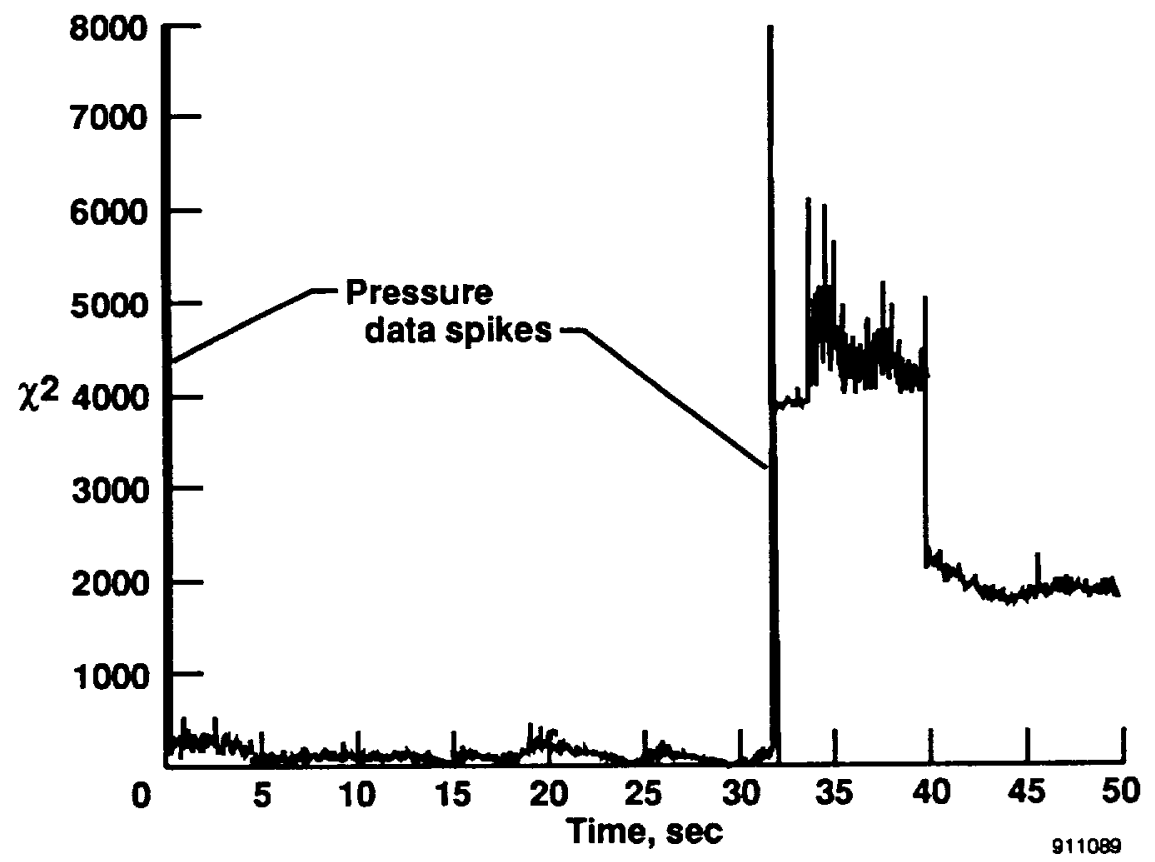

Figure 15(b) Chi-square value for diverged airdata. 
Next, the $\chi^{2}$ criterion is used to test for algorithm divergence. Here when the value of $\chi^{2} \geq 25$, a simple $3-\sigma$ test (based on the population variance for unfailed airdata) on the individual pressure residuals is performed. For failed pressures, the weight is set to zero. The resulting computed angle-of-attack time history is presented in figure 16(a). Only slight irregularities at the points of the spikes are distinguishable. The computed $\chi^{2}$ time history is presented in figure $16(\mathrm{~b})$. Only at the points of the spikes does the $\chi^{2}$ value become large. More sophisticated weighting schemes are currently being developed and will be applied in later tests using the HI-FADS data.

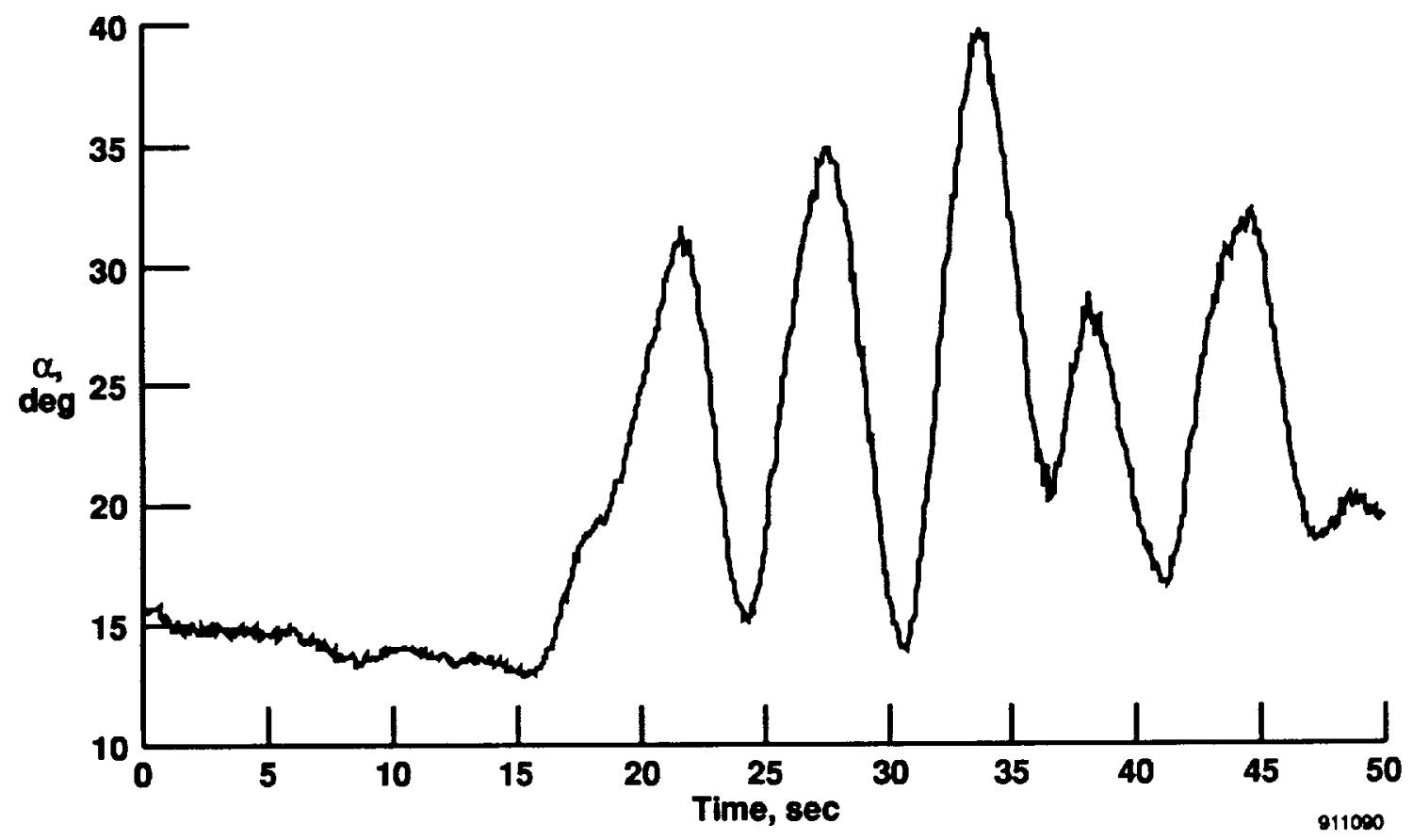

Figure 16(a) Converged airdata (divergence protected).

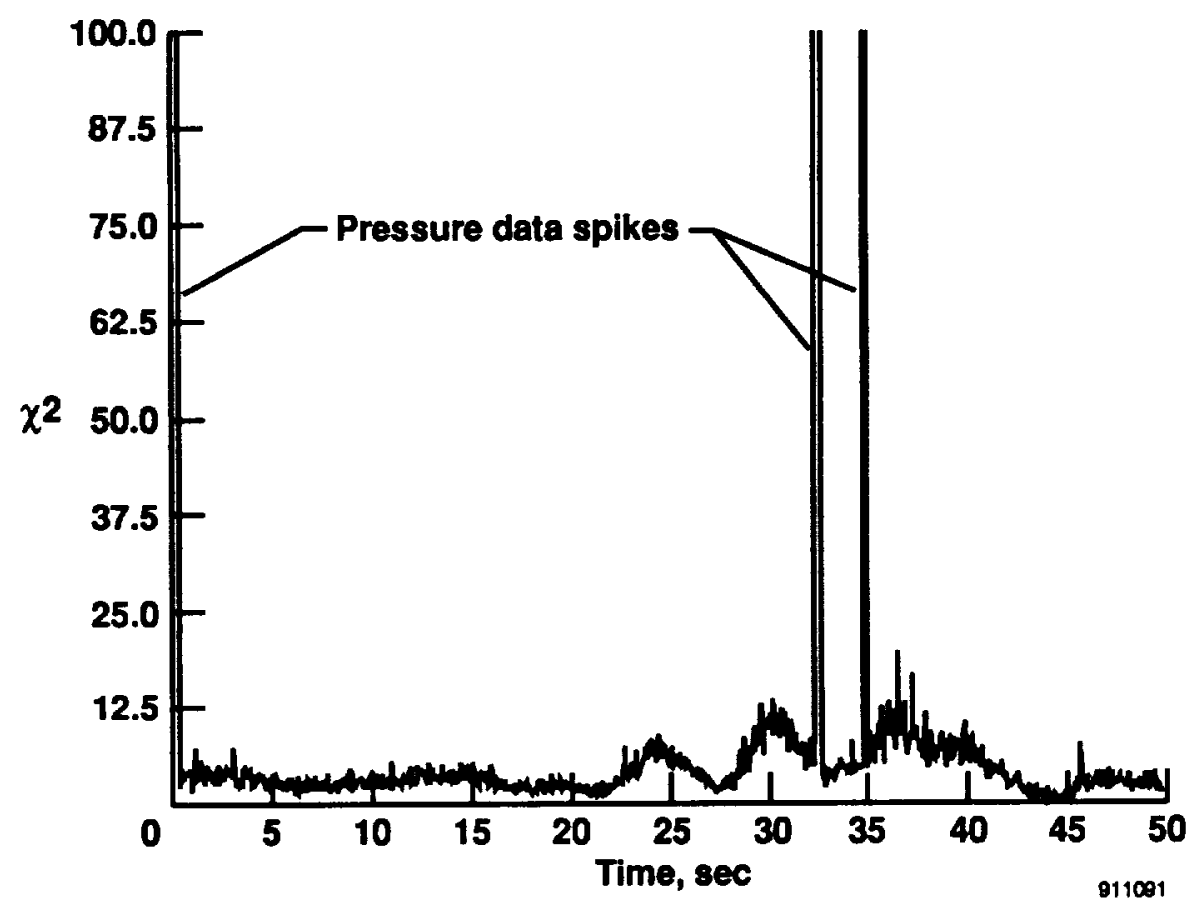

Figure 16(b) Chi-square value for converged airdata (divergence protected). 


\section{PROPOSED FUTURE WORK}

To flight demonstrate a real-time flush airdata sensing (RT-FADS) system, a collaborative effort between NASA Dryden, McDonnell Aircraft (McAir), and Honeywell Inc., is currently underway. This effort seeks to demonstrate in real time the capabilities of a FADS system onboard NASA Dryden's Systems Research Aircraft (SRA), an FA-18b. The RT-FADS system is based on the HI-FADS architecture, but will be performed in onboard processors and the evaluated airdata will be displayed to the pilot and also telemetered to ground in real time. The first flight of the system is anticipated to occur in April of 1992. Tests for Mach numbers up to 1.40 are planned.

\section{SUMMARY AND CONCLUDING REMARKS}

A prototype nonintrusive airdata system was installed and flight tested on the F-18 High Alpha Research Vehicle at the NASA Dryden Flight Research Facility. This system consists of a matrix of 25 pressure orifices arranged in concentric circles on the nose of the vehicle. Pressure was transmitted from the orifices to a multiport electronically scanned pressure module by way of lines of flexible pneumatic tubing. Outputs were digitized and telemetered to ground where they were recorded on tape for post-flight processing.

The HI-FADS system was calibrated using flight data. The calibration parameters relate effective angle of attack and angle of sideslip to freestream values, as well as account for compressibility and total energy loss at the sensor array. Details of the calibration procedure and calibration results were presented.

The HI-FADS algorithm, failure detection, and fault tolerance techniques were developed and presented. Flight results were processed and compared against reference airdata. Computations were performed using all 25-ports and a subset of 9-ports. Statistical analysis of residuals for both the 9-port and the 25-port analysis methods indicate that the random measurement uncertainty is approximately one-half degree in angle of attack and angle of sideslip, and better than 0.004 in Mach number. The extremely low residual mean values indicate that on a steady-state basis the HI-FADS system can be calibrated as accurately as the reference values to which the system is calibrated. Use of the failure detection and fault tolerance schemes was illustrated.

\section{REFERENCES}

1. Fisher, David F., Del Frate, John H., and Richwine, David M., "In-Flight Flow Visualization Characteristics of the NASA F-18 HARV Aircraft at High Angles-of-Attack," SAE 89-2222, Sept. 1989.

2. Henry, M.W., Wolf, H. and Siemers, Paul M., III, "Shuttle Entry Airdata System (SEADS): Optimization of Preflight Algorithm Based on Flight Results," AIAA 88-2053, May 1988.

3. Larson, Terry J., Whitmore, Stephen A., Ehernberger, L.J., Johnson, J. Blair, and Siemers, Paul M., III, Qualitative Evaluation of a Flush Air Data System at Transonic Speeds and High Angles of Attack, NASA TP-2716, 1987.

4. Larson, Terry J., Whitmore, Stephen A., and Siemers, Paul M., III, Subsonic Investigation of an All Flush Orifices Airdata System, NASA TP-1643, 1980.

5. Schneider, Edward T. and Meyer, Robert R., Jr., "F-18 High Alpha Research Vehicle Description, Results, and Plans," Society of Experimental Test Pilots (SETP), 1989 Report to the Aerospace Profession, Proceedings, 1989.

6. Gracey, William, Wind-Tunnel Investigation of a Number of Total-Pressure Tubes at High Angles of Attack: Subsonic, Transonic, and Supersonic Speeds, NACA TR-1303, 1957. 
7. Gracey, William, Measurement of Aircraft Speed and Altitude, NASA RP-1046, 1980.

8. Richardson, Norman R. and Pearson, Albin R., Wind Tunnel Calibrations of A Combined Pitot-Static Tube, Vane-Type Flow-Direction Transmitter, and Stagnation-Temperature Element at Mach Numbers from 0.60 to 2.87, NASA TN-D122, 1959.

9. Moes, Timothy R. and Whitmore, Stephen A., A Preliminary Look at Techniques Used to Obtain Airdata From Flight at High Angles-of-Attack, NASA TN-101792, 1990.

10. Geenen, Robert J., Moulton, Bryan J., and Haering, Edward A., "A System for Testing Airdata Probes at High Angles of Attack Using A Ground Vehicle," AIAA 91-0088, Jan. 1991.

11. Currie, I.G., Fundamental Mechanics of Fluids, McGraw-Hill Book Company, New York, NY, 1974.

12. Kuethe, Arnold M. and Chow, Cheun-Yen, Foundations of Aero-dynamics: Bases of Aerodynamic Design, Third Edition, John Wiley and Sons, New York, NY, 1976.

13. Anderson, John D. Jr., Hypersonic and High Temperature Gas Dynamics, McGraw-Hill Inc., New York, NY, 1989.

14. Whitmore, Stephen A., "Reconstruction of the Shuttle Reentry Air Data Parameters Using a Linearized Kalman Filter," AIAA 83-2097, Aug. 1983.

15. Whitmore, Stephen A., Formulation and Implementation of A Non-Stationary Adaptive Estimation Algorithm with Applications to Air-Data Reconstruction, NASA TM-86727, 1985.

16. Whitmore, Stephen A., Larson, Terry J. and Ehernberger, L.J., Air Position-Error Calibration Using State Reconstruction Techniques, NASA TM-86029, 1984.

17. Moes, Timothy R. and Whitmore, Stephen A., "Preliminary Results from an Airdata Enhancement Algorithm with Applications to High Angle-of-Attack Flight," AIAA 91-0672, Jan. 1991.

18. Brogran, William L., Modern Control Theory, Quantum Publishers Inc., New York, NY, 1974.

19. Bendat, Julius S. and Piersol, Allan G., Random Data: Analysis and Measurement Techniques, Wiley-InterScience Publishing Corp., New York, NY, 1971. 


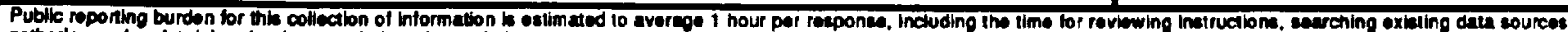

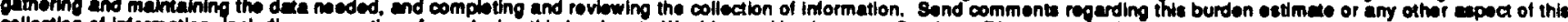

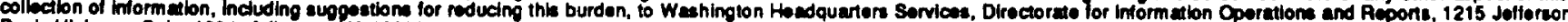
Davis Hiphway, Sube 1204, Arlington. VA 222024302, and to the Otfice of Management and Budget, Peperwork Reducton Propct (0704-0188). Washington, DC 20503.

\begin{tabular}{|l|l|l} 
1. AGENCY USE ONLY (Leavo blank) & 2. AEPORT DATE & 3. AEPOAT TYPE AND DATES COVEAED
\end{tabular} November 1991 Technical Memorandum

4. TITLE AND SUBTITLE

Development of a Pneumatic High-Angle-of-Attack Flush Airdata Sensing (HI-FADS) System

6. AUTHOR(S)

RTOP 505-68-40

Stephen A. Whitmore

7. PERforming ORganization mame(S) AND AdDREss(ES)

NASA Dryden Flight Research Facility

P.O. Box 273

Edwards, Califomia 93523-0273

6. Performing organization REPORT NUMEER

H-1766

9. SPONSOAINO/MONITOAINO AGENCY NAME(S) AND ADDAESS(ES)

10. SPONSORINOIMONITOAINO AGENCY REPORT NUMBER

National Aeronautics and Space Administration

Washington, DC 20546-0001

NASA TM-104241

11. SUPPLEMENTAAY NOTES

Presented as a conference paper at the Society of Automotive Engineers, Inc. (SAE)

Aerotech '91 Conference, Sept. 23-26, Long Beach, Califomia.

12a. DISTAIBUTION/AVAILABILITY BTATEMENT

12b. DISTRIEUTION CODE

Unclassified - Unlimited

Subject Category 06

13. ABSTRACT (Maximum 200 words)

A nonintrusive high-angle-of-attack flush airdata sensing system was installed and flight tested on the F-18 High Alpha Research Vehicle at the NASA Dryden Flight Research Facility. This system consists of a matrix of 25 pressure orifices arranged in concentric circles on the nose of the vehicle to determine angles of attack and sideslip, Mach number, and pressure altitude. During the course of the flight tests, it was determined that satisfactory results could be achieved using a subset of just nine ports.

\section{SUBJECT TERMS}

Airdata; Flush airdata; High angle of attack fault management; Chi square

15. NUMBEA OF PAOES 28

16. PRICE CODE AO

17. SECURITY CLASSIFICATION OF REPORT

Unclassified
18. SECURITY CLASSIFICATION OF THIS PAGE

Unclassified 18.

19. SECUAITY CLASSIFICATION OF ABSTRACT

Unclassified
20. LIMITATION OF ABSTAACT

Unlimited 
